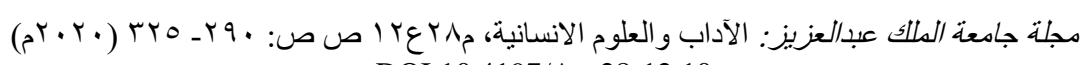

DOI:10.4197/Art.28-12.10

\title{
استخدام وسائل الإعلام التفاعلي لدى طالبات الدبلوم التربوي بجامعة جدة في ضوء بعض المتغيرات الديموغرافية
}

\author{
د. نبيلة محمد أمين بخاري

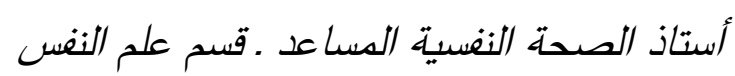

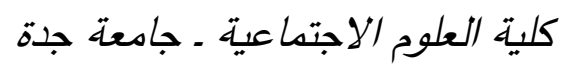

مwitter, Facebook, ) مستخص. يهدف البحث الحالي إلى الكشف عن نسب استخدام وسائل الإعلام التفاعلي (MySpace, Google+, WhatsApp لاى طالبات الدبلوم التربوي بجامعة جدة، والكشف عن الغرض من استخدام مواقع الإعلام التفاعلي، فضلاً الكثف عن الفروق في استخدام وسائل الإعلام التفاعلي وفقاً لمتغيرات (التخصص لتصن الدراسي ـ المستوى التعليمي للوالدين ـ مستوى الدخل)، تكونت العينة من ( · . ب) طالبة بالدبلوم التربوي بكلية

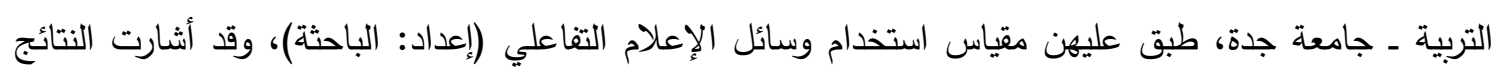

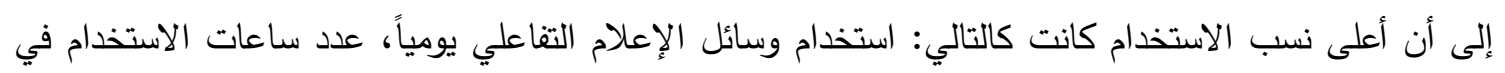

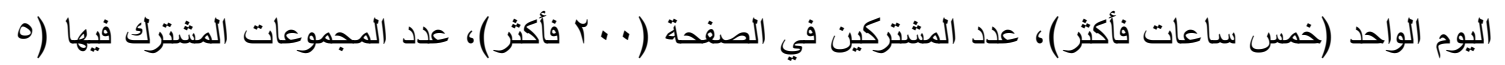
مجموعات)، عدد الزيارات للصفحات المفضلة يومياً أكثر من خمس مرات، واستخدام وسائل الإعلام التفاعلي في

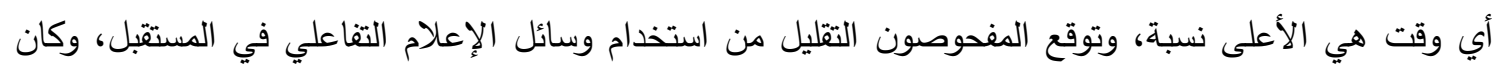

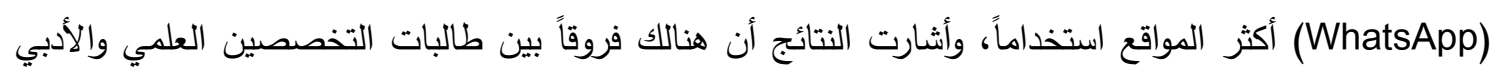
في استخدام وسائل الإعلام التفاعلي لصالح العلمي، بينما لم توجد فروق بين أفراد العينة في استخدام وسائل

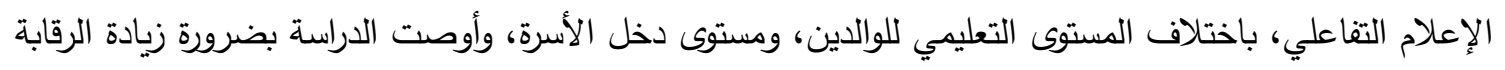
على مواقع التواصل الاجتماعي، وتفعيل دور الجهات ذات العلاقة في توجيه طالبات الجامعة نحو المواقع التي تساعد على تعزيز تثقافتهن.

الكلمات المفتاحية: وسائل الإعلام التفاعلي ـ طالبات الجامعة ـ المتغيرات الديموغرافية.

بقية العالم في قلب ثورة الإنترنت، والأجهزة الذكية، مقدمة ومشكلة البحث

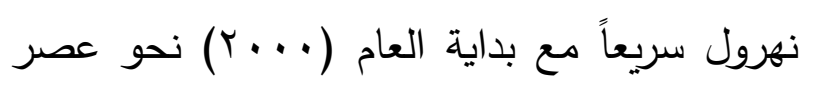
من غير سابق تمهيد يستغرق دائماً عشرات السنين

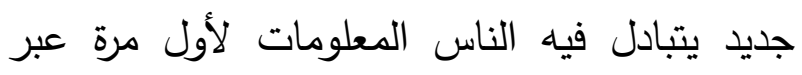

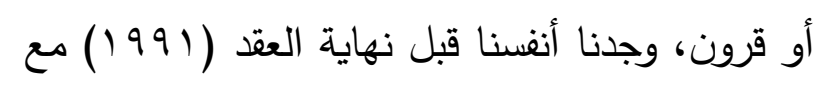


التفاعلي مثل Twitter, Facebook التي تتسم بعناصر الفورية، والتفاعلي، وتعدد الوسائط، والتحديث التي يلتف حولها الثباب ،كما أصبح المحرك الرئيس نحو تغيير وتعديل الاتجاهات والميول والأفكار لدى الثباب وقد يكون هذا التغيير في الاتجاه الإيجابي أو الاتجاه السلبي أو كليهما،

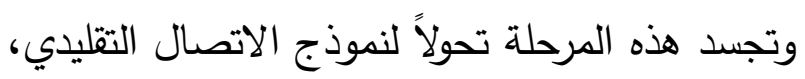
بما يسمح للفرد العادي بإيصال رسالته إلى من يريد، في الوقت الذي يريد بطريقة متعددة الاتجاهات وليس من أعلى إلى أسفل، وفق النموذج الاتصالي القديم

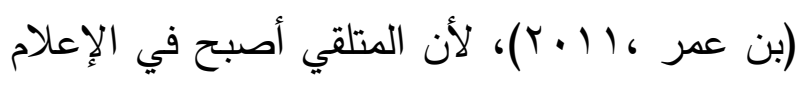
الجديد هو المرسل فلم يعد هو المستقبل فقط ولم يعد مسئولو الإعلام وقيادة الرأي العام هي التي تغرض رأيها ومنهجها ولكن الإعلام الجديد قلب المعادلة

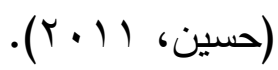
ويمكن القول أن الاعلام الاككتروني هو "عبارة عن نوع جديد من الاعلام يشترك مع الاعلام التقليدي في المفهوم، والمبادئ العامة والاهداف، وما يميزه عن الاعلام التقليدي أنه يعتمد على وسيلة جديدة من وسائل الاعلام الحديثة وهي الدمج بين كل وسائل الاتصال التقليدي، بهدف إيصال المضامين المطلوبة بأشكال متمايزة، ومؤثرة بطريقة أكبر، وتتيح الانترنت للإعلاميين فرصة كبيرة لتقديم موادهم الاعلامية المختلفة، بطريقة الكترونية بحتة دون اللجوء إلى الوسائل التقليدية كمحطات البث، المطابع وغيرها بطرق تجمع بين النص والصورة
وسائل اتصال متاحة لكل الناس حول العالم، نعيش اليوم عصر الاتصال الجديد، الذي افرزته التقنية الرقمية للمعلومات، والتفاعل الاجتماعي حولها

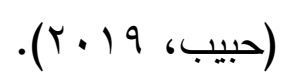

حيث شهدت الانسانية خلال السنوات الأخيرة تطورات تكنولوجية عديدة، لعل أبرزها تلك المتعلقة بتطور وسائل الإعلام والاتصال، وقد أحدثت هذه الوسائل ثورة معلوماتية في صفوف المجتمع عامة والثباب خاصة، وغدونا نتحدث عن منافسين جدد لوسائل الإعلام التقليدية، حيث ساهمت وسائل الإعلام التقاعلي في فتح آفاق جديدة لمجال الإعلام والاتصال، وتمكن مستخدمي هذه الوسائل الحديثة من تجاوز الحدود الزمانية والمكانية، والرقابة نحو الانفتاح على العالم الذي أصبح قرية كونية. فقد نتج عن التزاوج بين تكنولوجيا الإعلام والاتصالات ظهور ما يسمى بالإعلام الإكتروني، الذي يعتبر وسيلة تضمنت كل ما سبقها من وسائل الإعلام، بالإضافة إلى ما قامت به من دمج لأشكال الإعلام التقليدية مما أفرز صناعة إعلامية جديدة ومبتكرة، كسرت قاعدة المرسل والمستقبل المعمول بها في وسائل الإعلام التقليدي، لتصبح المعادلة أقرب إلى (الكل صناع الخبر والكل متلقي له) تحت شعار اصنع إعلامك بنفك (نادي، r I . r).

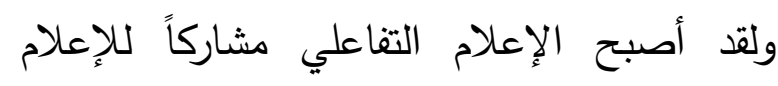
التقليدي كونه يحتوي في مضمونه على كافة الفنون الإعلامية والتقنيات الحديثة لمواقع وسائل الإعلام 
الحديثة بشكل عام في جميع الميادين، لمواكبة

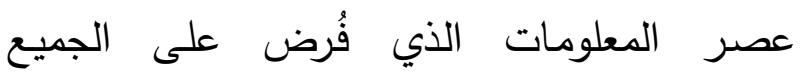

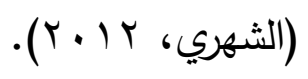

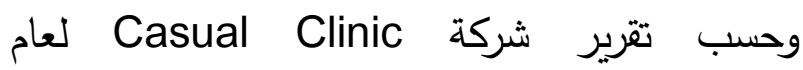

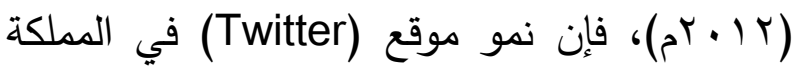
يعد ظاهرة نادرة، حيث صنفت السعودية بأنها الدولة

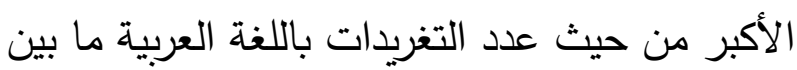
الدول الناطقة بها، فقد وصلت نسبة التغريدات العربية الصادرة من المملكة وحدها قرابة الـ (•r\%) من مجمل التغريدات العربية، واحتلت الرياض المركز العاشر عالميًا في عدد التغريدات الشهرية، التي تجاوزت (ب) مليون تغريده شهريًا (المدني، . $(r \cdot 10$

ومع تتامي اعتماد الأفراد على الإنترنت وتطور المواقع تعددت الاستخدامات من التصفح للبريد الإلكتروني ثم المنتديات وغرف الدردشة والرسائل النصية والفورية والمدونات حتى ظهرت المواقع التفاعلي كمصطلح أطلق على مجموعة المواقع الالكترونية التي ظهرت مع الجيل الثاني للويب،

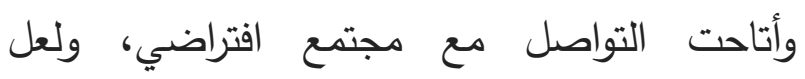
Face Book - My Space - Twitter أشهرها - Xing

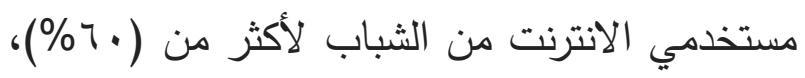
حيث وفرت تلك المواقع للمستخدمين بيئة تفاعلية Virtual Interactive افتراضية Environment
والصوت. والتي ترفع الحاجز بين المتلقي والمرسل

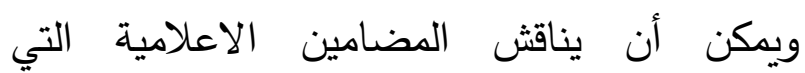
يستقبلها، إما مع إدارة الموقع أو مع متلقين آخرين.

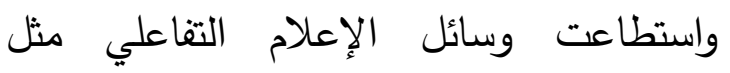
"Linkedln" وغيرها ك "Twitter" و و و "Facebook" في العالم وفي منطقة الثرق الأوسط على وجه

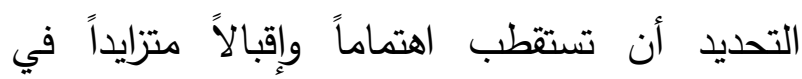

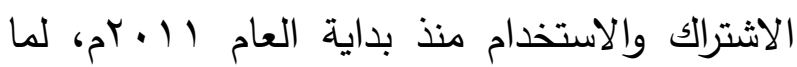
توفره هذه الوسائل من مساحات واسعة للتواصل

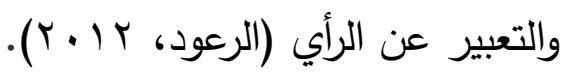

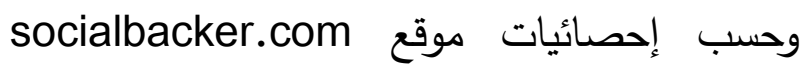
المتخصص في متابعة وسائل الإعلام التفاعلي على الإنترنت تأتي الولايات المتحدة الأمريكية الأكثر

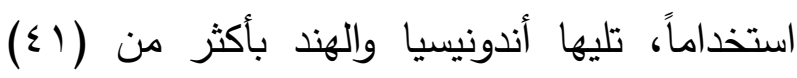
مليون مشترك ثم البرازيل بأكثر من (ب0) مليون مشترك، وفي العالم العربي تتصدر مصر القائمة بعدد مستخدمين أكثر من (9) ملايين مشترك، ثمان

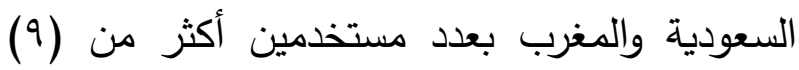
ملايين مشترك، ثم الجزائر بما يقارب (r) ملايين

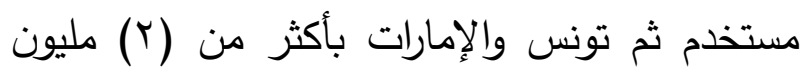

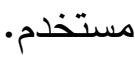
والمملكة العربية السعودية كأحد مجتمعات العالم المعاصر لم تكن بعيدة عن هذه الثورة فهي تشهـد

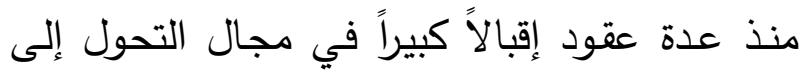
مجتمع تقني يقوم على الاستفادة من المزايا التي لئي تقدمها تقنية الاتصال بشكل خاص والتقنية 
الجغرافية بين ما نسبته (TV,I \% منهم لتشعرهم بالقرب النفي بأسرهم وعائلاتهم الذين يعيشون خارج

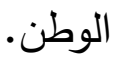

وفي هذا الصدد تشكل وسائل الإعلام الإكترونية

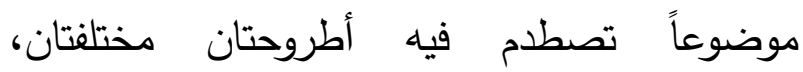
الأطروحة الأولى ترى في هذه المواقع فرصة للبشرية لتبادل الاتصال والمعرفة والقضاء على عوائق الزمان والمكان فتزيد في تقارب الناس وترفع من درجة تفاعلهم وتنشئ علاقات اجتماعية جديدة بين الأفراد (Beaudoin, 2008)، كما أن مواقع الشبكة الاجتماعية تجمع بين الثباب الذين لديهم اهتمامات

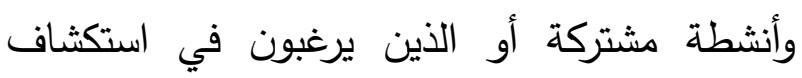

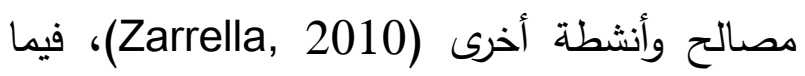
تتظر الأطروحة الثانية لهذه المواقع بأنها تشكل

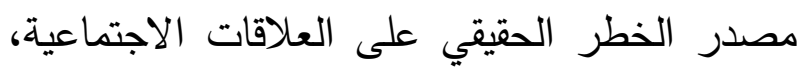
إذ تؤدي إلى ميلاد مجتمع يحمل عوامل القطيعة مع التقاليد الثقافية، كما تؤدي إلى العزلة وتئليع وتفكك نسيج الحياة الاجتماعية، ويرى هؤلاء أن وسائل الإعلام التفاعلي قد اقتحمت الحياة العائلية بحيث قللت من فرص التفاعل والتواصل داخل الأسرة (شليبي، T . . T)، فضلاً عن أنها تعرض الثباب والمراهقين

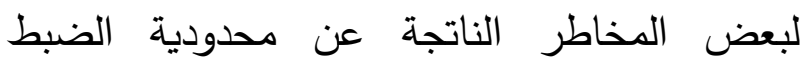
الذاتي، وزيادة التحديات العقائدية والاجتماعية والسياسية (أبو خطوة والباز، ع ( • Y).
وفكر واهتمام ووجدان وعقول الشباب وخاصة بعد نجاحها في جذب واستقطاب العديد من الفئات العمرية دونما اعتبار للفوارق الجغرافية والدينية والعرقية والجنسية والسياسية والاقتصادية، ليمتزج الاتصال الذاتي والشخصي والجمعي والجماهيري فى وائه بيئة واحدة أعادت تشكيل الحياة التفاعلي والاتصالية للفرد، وساهمت في التأثير على منظومة القيم والأخلاق التي تكون سلوك الفرد (حسن، 9 . . ץ). ويتسم المجتمع الافتراضي بمجموعة من السمات منها المرونة وانهيار فكرة الجماعة المرجعيّة بمعناها التقليدي، فالمجتمع الافتراضي لا يتحدّد بالجغرافيا

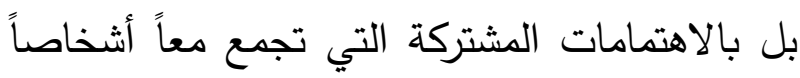

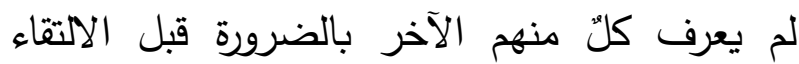

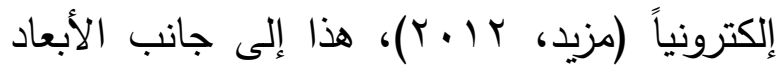
النفسية والتفاعلي والثقافية التي تركها الإنترنت بوصفه وسيلة اتصال إلكترونية حديثة على علاقات

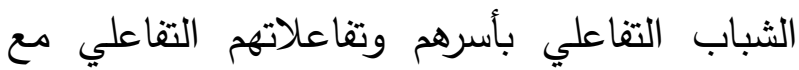

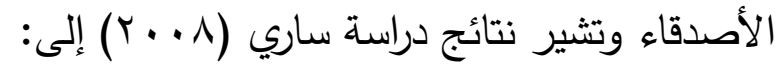

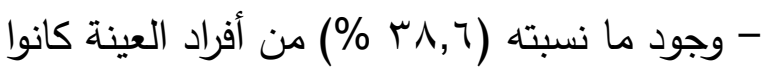
قد تحدوا آليات الضبط الأسري والتفاعلي. - تراجع في مقدار التفاعل اليومي بينهم وبين أسرهم وتراجع في عدد زياراتهم لأقاربهم. - وجود حالة من العزلة والاغتراب النفسي بين الثباب باعد بينهم وبين مجتمعهم إذ بلغت نسبة من

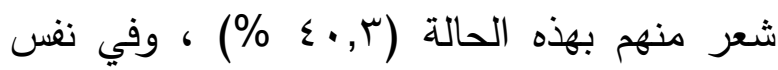
الوقت يعمل الإنترنت على اختزال المسافات 


\section{أهداف البحث}

هدف البحث الحالي إلى:

ا ـالكثف نسب استخدام وسائل الإعلام التفاعلي

Twitter, Facebook, My Space, Google+, ) (WhatsApp لدى طالبات الجامعة. r. الكشف عن الغرض من استخدام وسائل الإعلام التفاعلي لدى طالبات الجامعة. r. الكشف عن الفروق في استخدام وسائل الإعلام التفاعلي لدى طالبات الجامعة وفق متغيرات (التخصص الدراسي ـ المستوى التعليمي للوالدين مستوى الدخل).

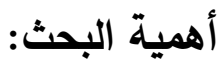
أولاً: الأهمية النظريـة - تناول هذا البحث ظاهرة هامة من ظواهر العصر الحديث وهي استخدام وسائل الإعلام التفاعلي، والبحوث في هذا الجانب (في حدود علم الباحثة) تعد قليلة لحد ما، لاسيما في المجتمعات العربية نظراً لحداثة هذه الوسائل وتتوعها. - أنها تستهدف فئة طالبات الجامعة اللاتي يعول عليهن في بناء المستقبل، خاصة أنهن نشأن مع نشأة هذا التيار التكنولوجي الجارف. ثانياً: الأهمية التطبيقية: - تزويد المكتبة العربية بأداة استبانة استخدام وسائل الإعلام التفاعلي. - محاولة التعرف على شبكات التواصل الاجتماعي التي تلجأ إليها طالبات الجامعة.
فعلاً، تشكل مواقع الاعلام التفاعلي ي ظاهرة.

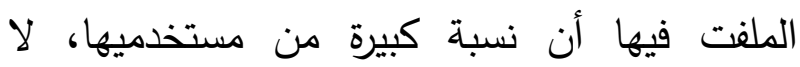
يدركون الأثر السلبي على مجتمعاتهم بسبب النشر المنقول من حسابات ومعرفات وهمية، ولكن رغم ذلك وهو الجانب الإيجابي في الثباب، فإن الأمل مناط بهم في حماية أوطانهم معلوماتي، فهم القوة الناعمة لبناء المجتمعات، وهم الثروة الحقيقية، وهم أيضا الميكنة للتقدم، وبالتالي سوف يوظفون دورهم في وسائل الاتصال الاجتماعي إيجابياً، لو زادهم وعيهم واكتسبوا خلفية ثقافية مبسطة. ومن هنا كان هذا البحث الذي يهتم بقضية محورية تتعلق بالأجيال الشابة في هذا العصر، ألا وهو استخدام مواقع الاعلام التقاعلي من خلال الكشف عن واقعه لدى طالبات الجامعة. مما سبق تتحدد مشكلة البحث الحالي في التساؤلات التالية: ا. ما نسب استخدام وسائل الإعلام التفاعلي Twitter, Facebook, My Space, Google+, ) ) لدى طالبات الجامعة؟ WhatsApp r.ما الغرض من استخدام وسائل الاعلام التفاعلي لدى طالبات الجامعة؟ r. هل توجد فروق في درجة استخدام وسائل الاعلام التغاعلي لاى طالبات الجامعة وفق متغيرات (التخصص الدراسي - المستوى التعليمي للوالدين - 
المقدمة مثل التعارف والصداقة والمراسلة والمحادثة الفورية، وإنشاء مجموعات اهتمام، وصفحات للأفراد والمؤسسات المشاركة في الاحداث والمناسبات، ومشاركة الوسائط مع الاخرين كالصور والفيديو

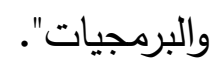

وهي حسب ريتز (Reitz, 2012:7) " خدمة إلكترونية تسمح للمستخدمين بإنشاء وتتظيم ملفات شخصية لهم، كما تسمح لهم بالتواصل مع الآخرين". ومهما اختلفت التعريفات في تحديد مفهوم الاعلام التفاعلي، إلا أنها تلتقي في نقطة واحدة وهي أنه لا يمكن تحديد مفهوم دقيق للإعلام التفاعلي دون ربطه بطبيعة المجتمع الذي يتوجه إليه بجميع مقوماته السياسية والاجتماعية والاقتصادية وما يرتبط بهذا الاتصال من ظروف زمانية ومكانية وكمية ونوعية وما شابه ذلك. وبشكل آخر فالإعلام التفاعلي هو عبارة عن استقصاء الانباء الآنية ومعالجتها ونشرها على الجماهير بسرعة. واستناداً لما سبق تعرف الباحثة وسائل الاعلام التفاعلي بأنها " تلك الأدوات، والأجهزة التي تُستخدَم؛ لنقل الأفكار، والمشاعر ، والآراء بين طرفَي عميّة الاتصّال، بغرض توصيل الفكرة أو الاقناع بها، أو الاستدراك حولها، كما توفر لمستخدميها فرصة للحوار وتبادل المعلومات ". وتتمثل أهم وسائل الإعلام التفاعلي فيما يلي: - Facebook : يعرفه قاموس الاعلام والاتصال Dictionary of media and communications
- قد تساعد نتائج البحث المختصون في المجالات النفسية على تقديم المساعدة والمساندة الممكنة لطالبات الجامعة للتخفيف من الآثار السلبية لظاهرة استخدام وسائل الإعلام التفاعلي، والتوجيه نحو الاستخدام الأمثل لها. أدبيات البحث: -

ا- وسائل الإعلام التفاعلي: Social) Networking sites) نظراً لحداثة مصطلح الإعلام التفاعلي فقد اختلف العلماء والخبراء في وضع تعريف محدد له، وفيما يلي استعراض لبعض التعريفات التي تتاولته:

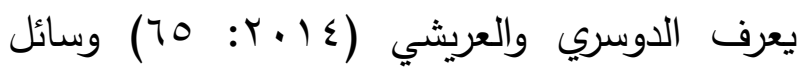
الإعلام التفاعلي بأنها "مواقع على شبكة الأنترنت توفر لمستخدميها فرصة للحوار وتبادل المعلومات والآراء والأفكار والمشكلات من خلال الملفات الشخصية وألبومات الصور وغرف الدردشة وغير ذلك"

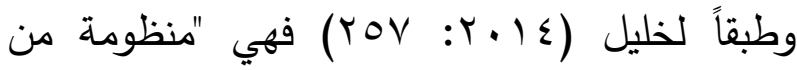
الوسائل التفاعلي الإكترونية التفاعلي، تسمح لمستخدميها بإنشاء صفحات وتكوين صداقات وتعديل ونقد ومناقشة ما يتم عرضه من معلومات".

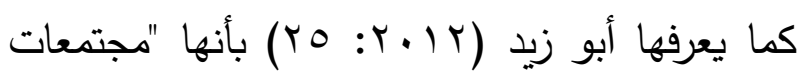
إلكترونية ضخمة تقدم مجموعة من الخدمات التي من شأنها تدعيم التواصل والتفاعل بين أعضاء الشبكة التفاعلي من خلال الخدمات، والوسائل 
بأنه موقع خاص بوسائل الإعلام التفاعلي أسس عام الأصدقاء المسلين في الخدمة بالإضافة إلى إلى

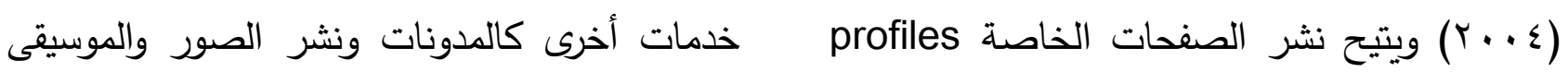
ووضع في البداية لخدمة طلاب الجامعة وهيئة ومقاطع الفيديو والمجموعات البريدية وملفات التدريس والموظفين ثم اتسع ليشمل كل الأشخاص المواصفات الشخصية للأعضاء المسجلين، أنثأ عام

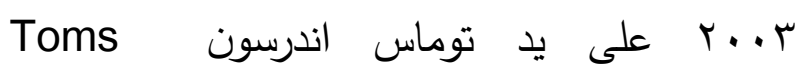
.( Marcel, 2009:117)

$$
\text { Anderson }
$$
-Google+ بواسطة شركة جوجل، تم إطلاقها رسمياً يوم (28) يونيو، (2011)، ولكن لم يكن التسجيل مسموح إلا بواسطة الدعوات فقط بسبب وجود الخدمة في الطور التجريبي، ولكن في يوم (20) سبتمبر،

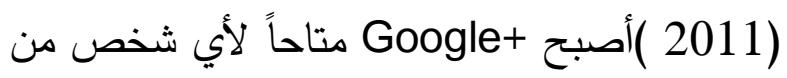
سن (1) فما فوق للتسجيل بدون الحاجة لأي دعوة من أي شخص آخ، ونشأ Google+ من خلال

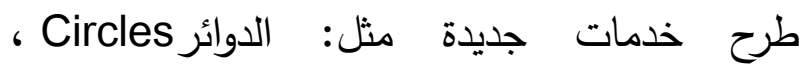
مكالمات الفيديو Hangouts ، الاهتمامات Huddles والمحادثات الجماعيةSparks

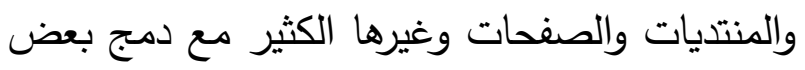
خدمات جوجل القديمة مثل : صدي جوجل Google الملف الثخصي: Google Buzz profile 11) (ويكيبيديا الموسوعة الحرة، صموئيل تان، $\cdot(r \cdot \lambda$

خصائص الاعلام التفاعلي: يتمتع الإعلام التفاعلي كما يشير شفيق كل من الاعل

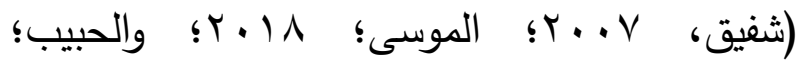

، Twitter والتي تسمح لمستخدميه بإرسال تحديثات Tweets عن حالتهم بحد أقصى (•气 (1) حرفاً للرسالة الواحدة، وذلك مباشرة عن طريق موقع (Twitter)، أو عن طريق إرسال رسالة نصية قصيرة (SMS)، أو برامج المحادثة الفورية أو التطبيقات التي يقدمها لئها المطورون مثل (Face Book \& Twitter) وتظهر تلك التحديثات في صفحة المستخدم ويمكن لأصدقائه قراءتها مباشرة من صفحتهم الرئيسية، أو

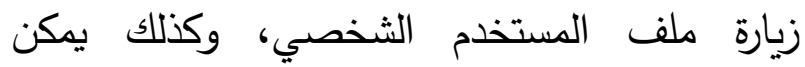

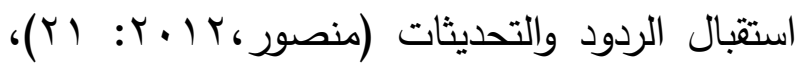
ويعد موقع Twitter من أهم وأثـهر وسائل

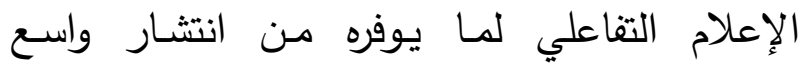
للرسائل القصيرة والروابط والملفات التي يمكن تبادلها بين مشتركيه، فالخبر لن يستغرق من الوقت

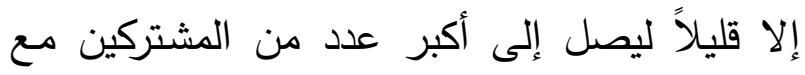

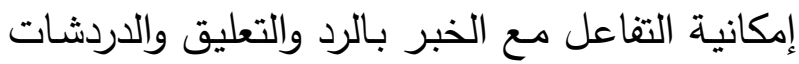
العامة و والخاصة-English, \& Duncan). Howell, 2008 :597) - موقع يقدم خدمات الوسائل : My Space التفاعلي على الويب، حيث يقدم خذمات تفاعلية بين 
أن القدرة على تزييف المعلومة قد ازدادت كثيراً مع

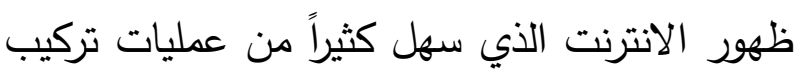
الصور وتعديل الأصوات وغيرها. - خاصية الانفتاحية: ونسبة كبيرة منه تلسم وغيرها.

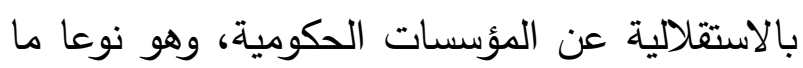
مجاني وساهم إلى حدود معينة في إضعاف الهيمنة الكبيرة لرأس المال والثركات الكبرى والحكومات

$$
\text { على الإعلام في العالم. }
$$

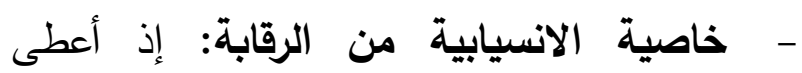
الحرية المطلقة وتخطى الحدود والحواجز المحلية والدولية وحدود القانون والرقابة المرتكزة على تقييد حرية الاعلام والمعتقد والتعبير في معظم بلدان العالم، فهو يتميز بسرعة تغطية الاحداث ونقل الخبر

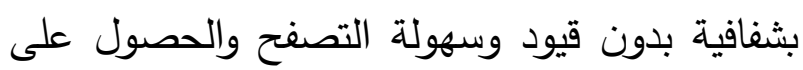
المعلومة والبحث عنها، وسمح للفرد من إبداء رأيه

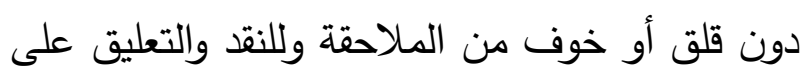
الموضوع التفاعلي. - خاصية التعددية الثقافية: فالإعلام الإككتروني يسر موضوع التعبير عن الذات والحوار الحضاري، إذ روج لثقافة احترام الرأي الأخر عن طريق لتوفير لتوفير

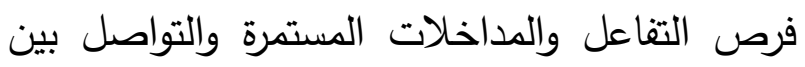
الإعلامي والجمهور وبطرق مختلفة، وأعطى فرصة ولة للجمهور من مختلف شرائح المجتمع لأن يكونوا إعلاميين من خلال مساهماتهم وكتاباتهم وتقديمهم لانح البرامج الاعلامية المحترفة وتبادلها فيما بينهم وعدم ودان اقتصارها على النخب.
(Y) بمجموعة من الخصائص التي تميزه عن بقية أنواع الإعلام الأخرى وهي: بلي: - خاصية التوفر: فالإعلام التفاعلي متوفر دائما

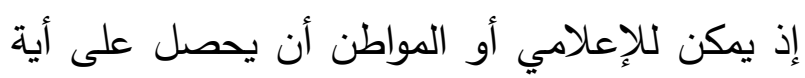

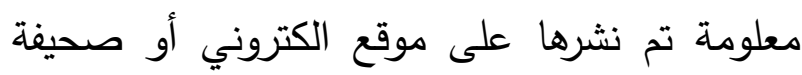

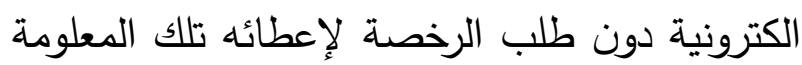
وفي أي وقت كان، ويوفر أرشيفاً إعلامياً إلكترونياً للجميع دون قيود. - خاصية الثمولية: أي التتوع والثمول في المحتوى، إذ كان الإعلامي في الاعلام التقليدي

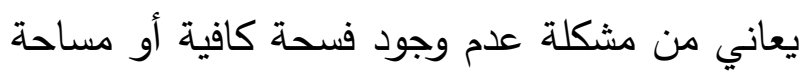
مخصصة لطرح موضوع أو إنجاز عمل إعلامي أو فئي

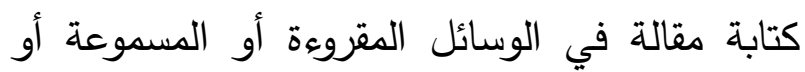
المرئية، لكن بفضل الانترنت الذي سمح بأنشاء مواقع ومدونات وصحف ومجلات الكترونية. - خاصية المرونة: تبرز خاصية المرونة بشكل جيد بالنسبة للمتلقي (مستخدم الانترنت) إذ يمكن لله

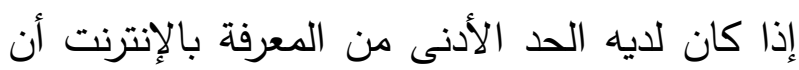

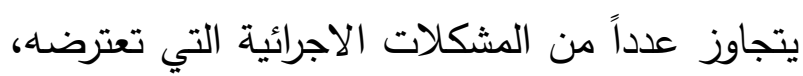
وكلما ازدادت قدرات الكومبيوتر تزداد مرونة التعامل

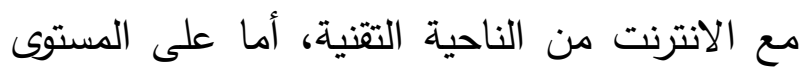
الإعلامي فتبرز خاصية المرونة من خلال قدرة

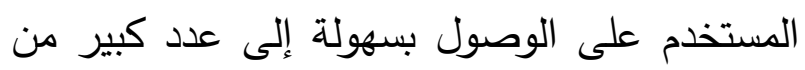

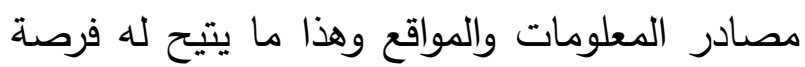
انتقاء المعلومات التي يراها جيدة وصادقة والتمييز بينها وبين المواقع التي تقدم معطيات مزيفة مع العلم 
عام وانخفاض تكلفة أسعار النشر الالكتروني مقارنة بأسعار النشر الورقي.

- خاصية المستقبلية: انه اعلام المستقبل، باعتماده على التكنولوجيا الحديثة بما يخفض من تكاليفه ويوسع من دائرة مستخدميه، فانتشار أجهزة النشر الالكتروني ووسائل الاتصال الإكترونية المحمولة في كف اليد والتي يسنطيع حاملها الدخول على الانترنت ومطالعة موقعه الالكتروني المفضل

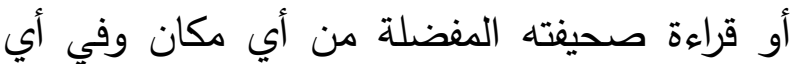
زمان، وكل ذلك يصاحبه استمرارية انخفاض أسعار هذه الأجهزة. - خاصية التفاعلية: سرعة الاجعة. وسهولة مناقشة الحدث او الموضوع إذ أدخل الجمهور كثريك أساسي في صنع محتوى الاعلام ومكّن الجمهور من أن يتفاعل مع المادة الإعلامية من خلال النص المكتوب والصوت والصورة والفيديو وحفظ نسخة من النص وسهولة الرجوع للنص في أي وقت أو إرسالها لشخص آخر، أو التعليق على

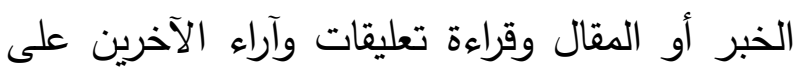

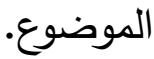
- خاصية التحديث: إذ يتم تحديث وتجديد الأخبار والمواد الاعلامية باستمرار دون مواعيد ثابتة، فالمحتوى الإعلامي الإلكتروني يتمتع بالسبق والقدرة على التفاعل واستخدام الصورة ومقاطع الفيديو، والخلفيات والمعلومات الأساسية والتحليلات ومقالات
- خاصية التواصلية: ساهم الاعلام التفاعلي بشكل ملحوظ في بناء جسور من التواصل بين القائم

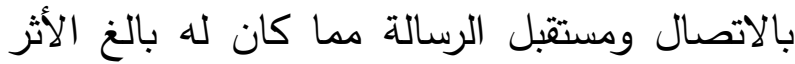
في تفاعل كل من الجانبين مع الأخر حيث أتاحت التكنولوجيا الرقمية أداة تمكن الجمهور من التعبير عن رأيه حول المادة المقدمة من حيث تبادل التعليقات وتشكيل شبكة للاتصالات والتواصل التجمع بين الكثير من التوجهات وتتمية الحوار الهادف والتعود على تقبل الآخر مهما اختلفت لئت

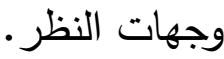
- خاصية التطور السريع: ان الاعلام التفاعلي يتطور بشكل سريع ومتواصل وأصبح ظاهرة عالمية لا يمكن الاستغناء عنها بحيث أصبح الاداة الاساسية في تسيير الاقتصاد الرأسمالي المعولم والإدارة الحكومية وذلك بفضل الانترنت الذي يعتبر وسيلته الاساسية، فالإحصائيات والدراسات العالمية تثير إلى ان استخدام الانترنت في العالم يتزايد بشكل كبير جدا، ويتطور بشكل سريع ومتواصل. - خاصية البناء الثقافي: إذ يساهم في انتشار

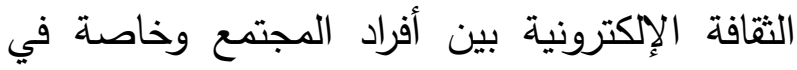
مجال التعليم الإلكتروني، والحقيبة الإكترونية للطالب، وزيادة استخدام التسويق الإكتروني أو الو التجارة الإلكترونية و هي عملية ترويج الأعمال والبيع للعملاء من خلال استخدام الانترنت، بالإضافة إلى ارتفاع أعداد مستخدمي الانترنت بشكل 
أعداد ورقية، وفي نفس الوقت تحاول إنشاء موقع لها على شبكة الانترنت. ثانياً: دراسات سابقة: فيما يلي استعراض لبعض الدراسات السابقة ذات الصلة بموضوع البحث:

قامت حنفي (ץ+..r) بدراسة ارتكزت على تحليل أثر استخدام أجهزة الحاسب الثخصي كوسيلة للاتصال عبر شبكة الانترنت على التفاعل

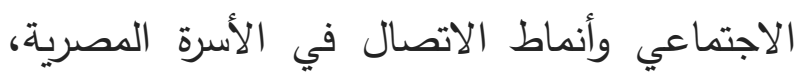

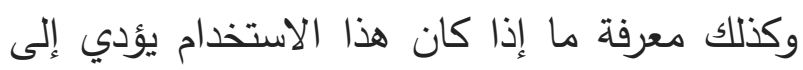

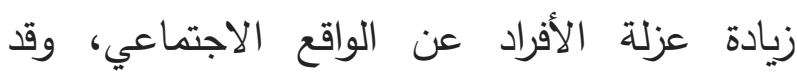
استخدمت الدراسة منهج المسح، وأجريت على عينة الإني

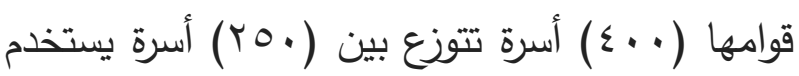

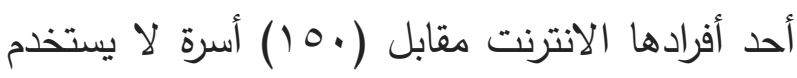

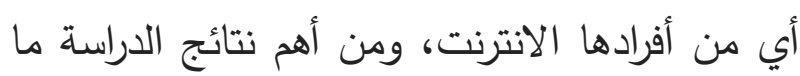

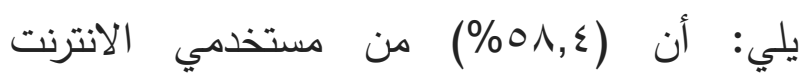
يستخدمونها من أجل المشاركة في المناقشات ومساعدة الآخرين في اتخاذ القرارات، وتبين أن ما هات

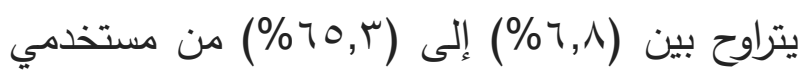
الانترنت أفادوا بوجود أنماط من الاتصال داخل الأسرة ترتبط باستخدام الانترنت، وأن الأسر متوسطة الأصناف المستوى الاقتصادي هي الأكثر استخداماً لشبكات

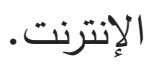

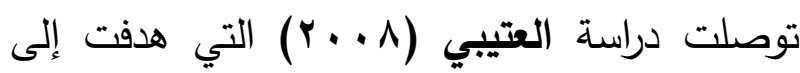

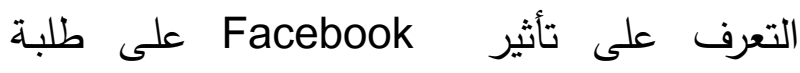
الجامعات السعودية، إلى أن نسبة انتشار استخدام
الرأي ذات العلاقة، مما يضفي تفاعلا حقيقياً مع المواد الإعلامية.

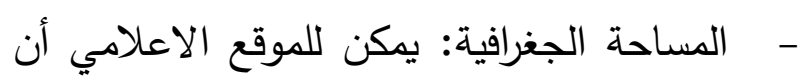
يصل - عن طريق الانترنت - إلى مختلف أنحاء العالم على عكس عدد كبير جدّا من وسائل الاعلام التقليدية التي تكون مقيدة ـ في أغلب الاحيان بحدود جغرافية محددة. وحتى إذا تمكنت بعض لبن

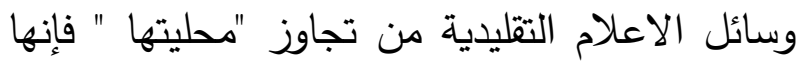
لا تضمن نشر رسائلها الاعلامية إلا على على عدد الاعد محدود من المتلقين في العالم، لذلك تسعى غالبية

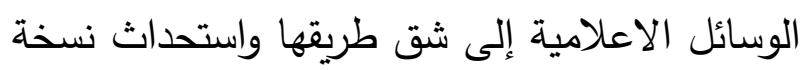
الكترونية لها في الانترنت. - عامل الكلفة: يبرز هذا العامل خاصة على التيرنى مستوى الصحافة المكتوبة، وبشكل أكبر عندما يتم تأسيس موقع إعلامي إلكتروني من حيث أنه يوفر

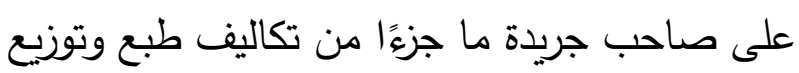
النسخة الورقية للجريدة ويضمن لله في الوقت نفسه عددا أكبر من القراءة، ولكن هنالك إشكالية تعترضنا

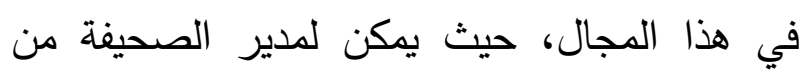
تغطية ميزانية الجريدة من خلال النسخة الورقية، ويمكن أن يغطي جزءا آخر من الميزانية من هن

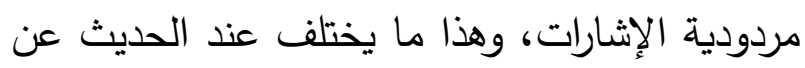
تأسيس موقع إلكتروني للصحيفة من ناحية المردودية وهنا نلاحظ عامل الكلفة بالنسبة للصحيفة، فالصحيفة الناجحة تحاول أن توافق بين إصدار 
ولا يشاهدون التلفاز كثيراً، ويلعبون عدداً أقل من

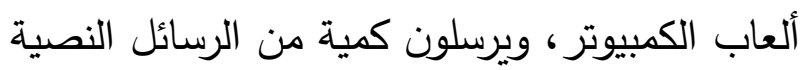

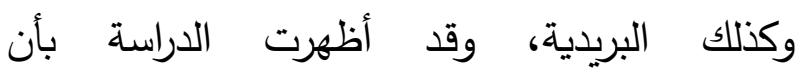
نحو(س\%\%) من الذين شاركوا في الدراسة المسحية،

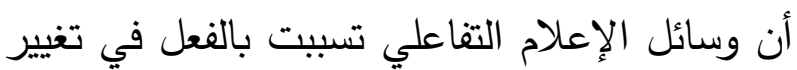

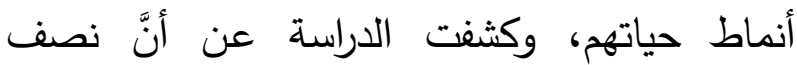
مستخدمي الإنترنت في بريطانيا هم أعضاء في أحد

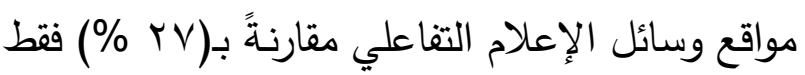

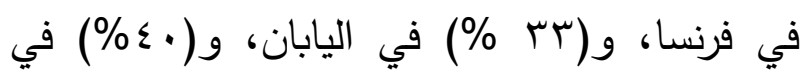
الولايات المتحدة.

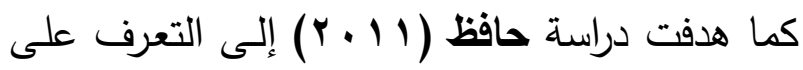
الدوافع الحقيقيـة للتواصل بين الثباب الجامعي

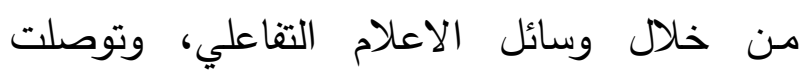

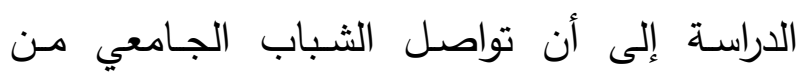
خلال وسائل الإعلام التفاعلي يعد ظـاهرة اجتماعية أكثر منها ضرورة أحدثتها التكنولوجيا الحديثة، وأظهرت أن إدمان الفئة الثبابية على الاستخدام

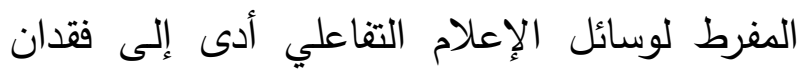

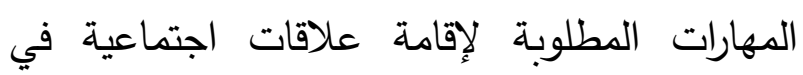
البيئة المجتمعية الواقعية وتراجع الاتصال الثخصي لإسهي

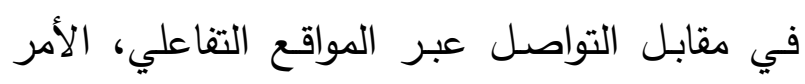
الذي يؤدي إلى جنوح الشباب نحو الاغتراب التفاعلي. في حين قام البلوشي ( 11 ـ ب) بدراسة بعنوان "أثر وسائل الإعلام التفاعلي على العزلة الاجتماعية للى لـئي طلبة الكويت المغتربين في جمهورية مصر العربية"،
"الفيس بوك" بين طلاب الجامعات السعودية وطالباتها بلغت (\%VV) وأن دور الأهل والأصدقاء

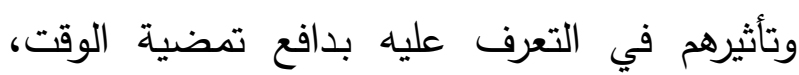

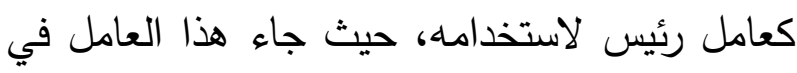

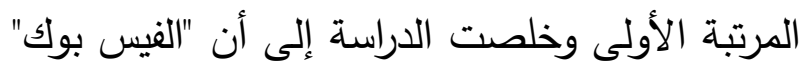

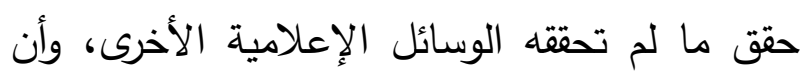
استخدام الفيس بوك كان له تأثيره على الثخصية أكثر من الوسائل الإعلامية الأخرى، وأشارت الدراسة إلى أن الإيجابيات التي يراها مستخدمو الإعلئ أنه يساعدهم في تحصيلهم العلمي (Facebook) وتبادل المعلومات، كما يزيد من التواصل والترابط التفاعلي بين الأصدقاء و ويساعد على إبراز المواهب وصقلها، مبينة أن السلبيات التي تكمن في ولاهي تأثيره على الارتباطات التفاعلية والأسرية نتيجة الاستخدام المفرط للموقع لساعات طويلة. في حين هدفت دراسة (Michel, 2010) إلى التعرف إلى أثر استخدام وسائل الإعلام التفاعلي

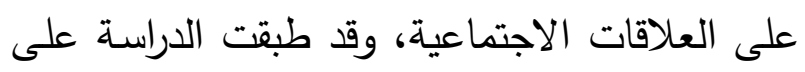

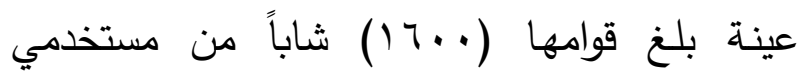
وسائل التوصل التفاعلي في بريطانيا، وقد أظهرت النتائج أنَّ أكثر من نصف الأشخاص البالغين الذين ولني

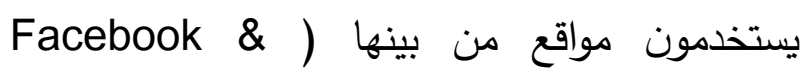
(YouTube على شبكة الإنترنت من ذلك الوقت الذي يقُضُونه

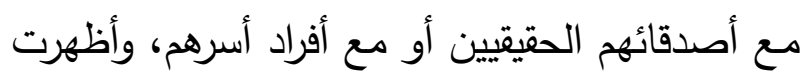

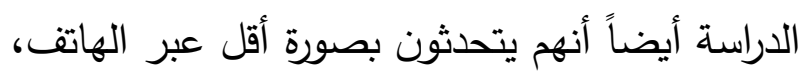


الترتيب: جاء الفيس بوك في الترتيب الأول ، ويليه

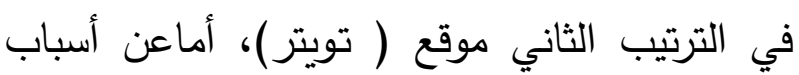
تفضيل الشباب المواقع الاجتماعية فقد تمثلت في

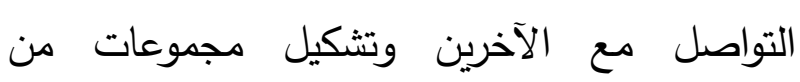
الأصدقاء.

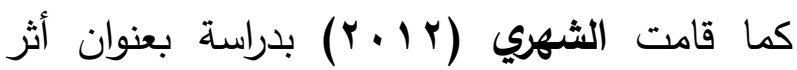
"استخدام وسائل التواصل الإككترونية على العلاقات الاجتماعية"، هدفت هذه الدراسة إلى التعرف على الإلى

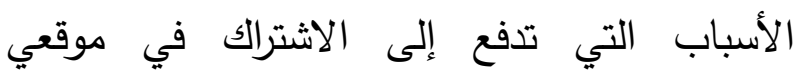
Facebook العلاقات الاجتماعية عبر هذه المواقع، والكثف عن

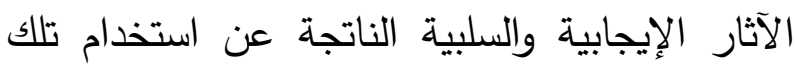
المواقع، طبقت الدراسة على عينة تتكون من (10. (1) طالبة من جامعة الملك عبد العزيز بطريقة قصدية،

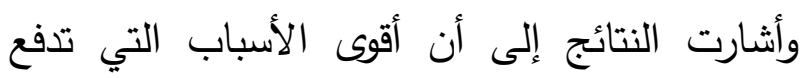

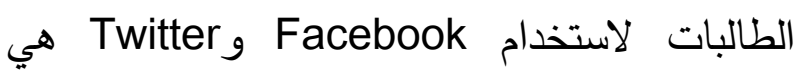
سهولة التعبير عن آرائهن واتجاهاتهن الفكرية التي لا يستطعن التعبير عنها صراحة في الواقع، وأشارت النتائج كذلك أن الطالبات استقدن من هذئ هذين الموقعين في تعزيز صداقاتهن القديمة والبحث عن صداقات جديدة، والتواصل مع أقاربكن البعيدين مكانياً، وأثبتت النتائج أيضاً وجود علاقة ارتباطية عكسية بين متغيري العمر والمستوى الدراسي وبين أسباب الاستخدام وطبيعة العلاقات الاجتماعية.

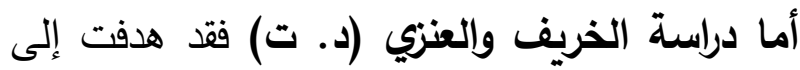
التعرف على مدى انتشار استخدام وسائل التواصل
أجريت الدراسة على عينة من (IM) (Y) طالباً وطالبة، ومن أهم النتائج التي توصلت إليها أن تقريباً من عينة الدارسة المستخدمين (\%rV) للإنترنت قد تعلموها بمفردهم ودون مساعدة أحد، وأن (•؛٪\%) من إجمالي العينة قد تعلموا استخدام الإنترنت من خلال الأصدقاء والأقران، وأثشارت النتائج إلى ارتفاع متوسط عدد ساعات استخدام الإنترنت في الأيام العاديـة بالنسبة للذكور (r,10)

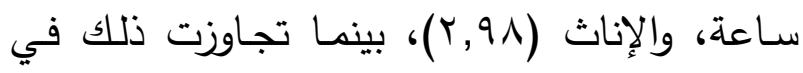
أيام العطل والإجازات لتصل إلى (10,؟) سـاعة

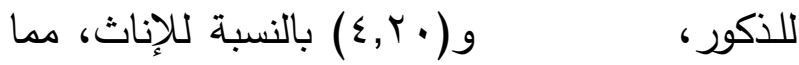
أوجد أثراً سلبياً على الطلبة في مجمل علاقاتهم

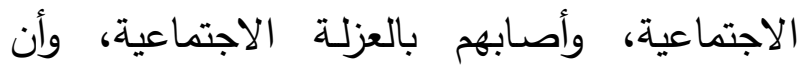
معظمهم أصبحوا يفضلون العالم الافتراضي الذي واجي توفره هذه الوسائل لإشباع رغباتهر.

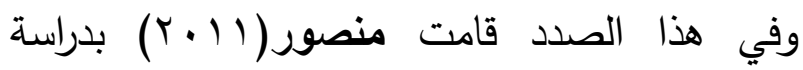
هدفت إلى التعرف على دوافع مشاركة الشباب في الحملات التي تتظمها مواقع الإعلام التفاعلي التعادهال

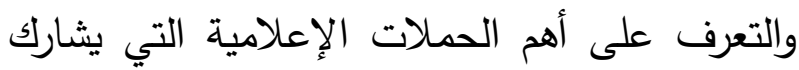

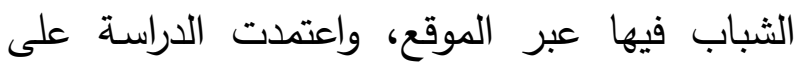
منهج المسح لعينة من جمهور الثباب الجامعية، وقامت الباحثة باختيار عينة عمدية من الثباب

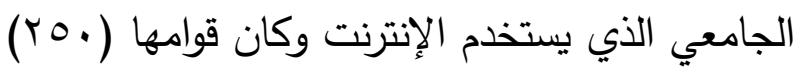
بجامعة قناة السويس، واعتمدت الدراسة على استمارة استبيان كأداة لجمع البيانات، ومن أهم النتائج التي توصلت إليها الدراسة، جاءت المواقع الاجتماعية في 
شبكات التواصل الاجتماعي على الثباب السعودي، فضلاً عن التعرف على معوقات شبكات التواصل الاصلئل الاجتماعي في تعزيز ثقافة الثباب السعودي، وأخيراً

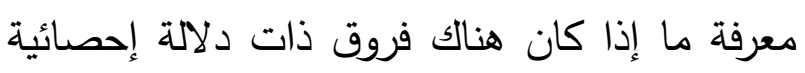

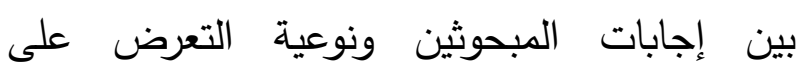
المتغيرات الثخصية التالية: العمر ، مستوى المعيشة.

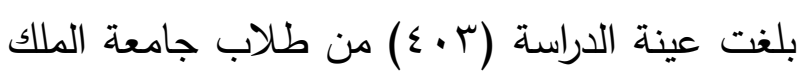

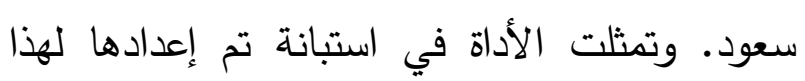

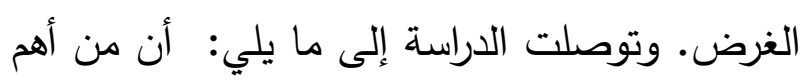
أدوار شبكات التواصل الاجتماعي في تعزيز ثقافة

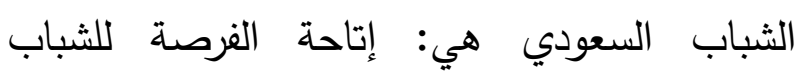
السعودي للتعبير عن آرائه وأفكاره، والاتصال والتواصل الثقافي مع الآخر، والمساهمة في تعزيز التفاعل والحوار مع الآخرين، ومن أهم إيجابيات

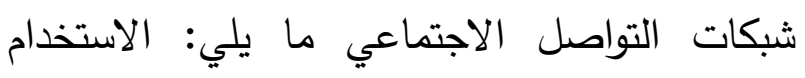
الجيد لشبكات التواصل الاجتماعي يؤدي إلى اتخاذ الإئل

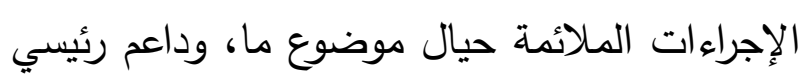

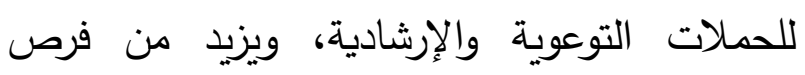
المشاركة الفعالة من قبل الشباب حيال الموضوعات ولات الثقافية المختلفة، أما أهم سلبيات شبكات التواصل

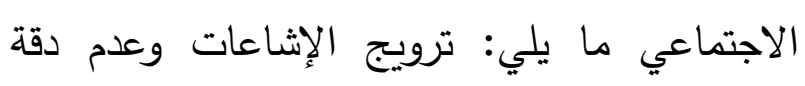

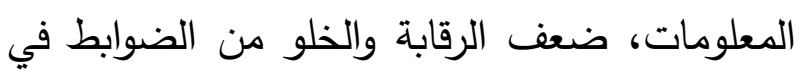

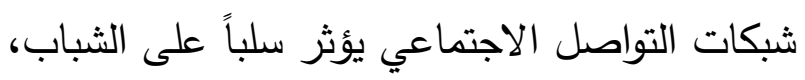
وانتشار الأفكار الهدامة وغزوها لعقول الثباب. وأخيراً اتضح أن من أبرز المعوقات التي تواجه التهار التهابه

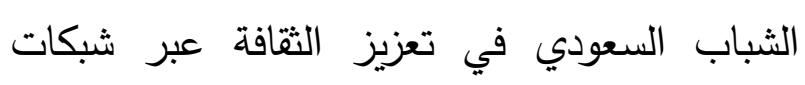
التواصل الاجتماعي ما يلي: كثرة مواقع التسلية
الاجتماعي بين الثباب السعودي وعلى وجه الخصوص في المنطقة الثرقية بالمملكة العربية السعودية، والكثف عن الفروق في استخدام وسائل

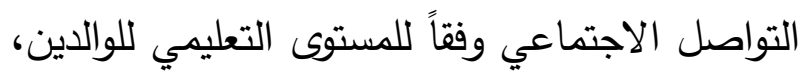
والدخل الثهري للأسرة، تكونت عينة الدراسة من الأن

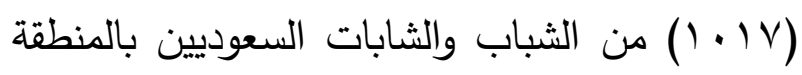

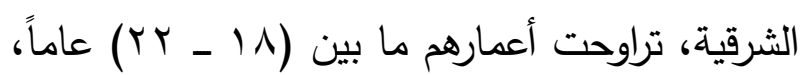

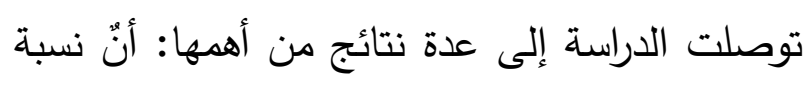

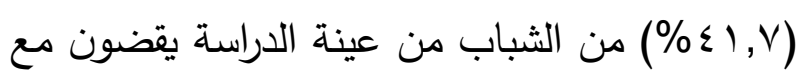

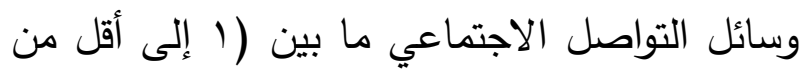

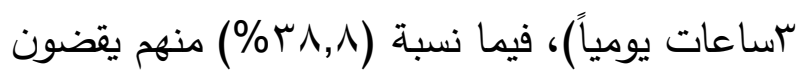

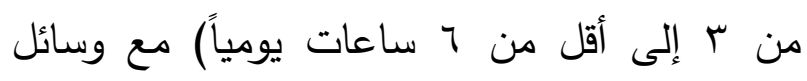

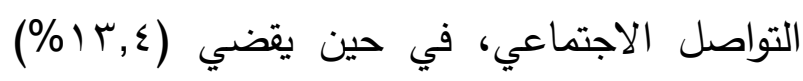
من الثباب أكثر من (T ساعات يومياً)، وأخيرا

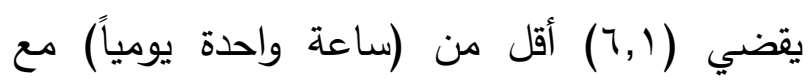

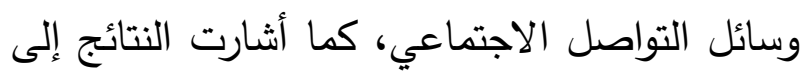

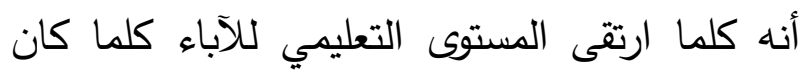
إدراكهم لهذا الانتشار الإكتروني بشكل أكبر، فتزيد

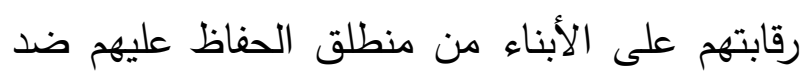

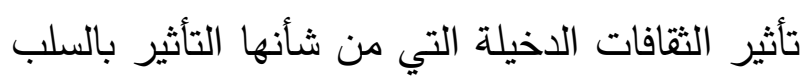

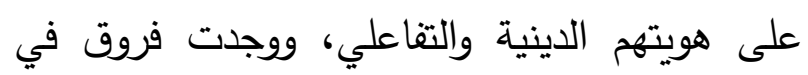
استخدام وسائل التواصل الاجتماعي تبعاً لمستوى ولئي الدخل الثهري لصالح الدخل المرتفع.

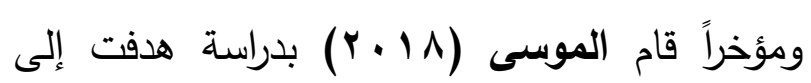
معرفة دور شبكات التواصل الاجتماعي في تعزيز ثقافة الثباب السعودي، ومعرفة إيجابيات وسلبيات 


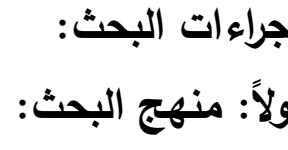

باعتبار المنهج هو القاعدة المستخدمة في جميع البحوث العلمية، ونظراً لطبيعة الموضوع فقد تم الاعتماد على المنهج الوصفي الارتباطي والمقارن لمناسبته لأهداف وطبيعة البحث. ثانياً: عينة البحث: تم اختيار العينة من طالبات الدبلوم التربوي بكلية التربية ـ جامعة جدة بطريقة عشوائية، وقد بلغ عدد

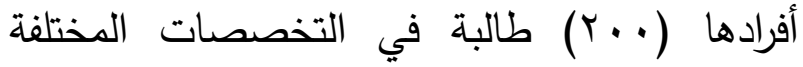
(علمي - أدبي)، (IVV (لالبة بالتخصص العلمي، rی طالبة بالتخصص الأدبي). تراوحت أعمارهن بين (YY - Y (Y) عاماً، بمتوسط حسابي وقدره

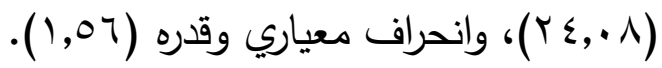
ثالثاً: أدوات البحث: (أ): استبانة استخدام وسائل الإعلام التفاعلي (إعداد: الباحثة):

قامت الباحثة بتصميم هذه الاستبانة بهدف قياس استخدام وسائل الإعلام التفاعلي لدى طالبات الدبلوم التربوي بجامعة جده، وذلك بعد الاطلاع على الأدب النظري وعلى مقياس استخدام وسائل الإعلام

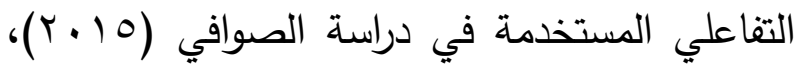
ودراسة حمودة (r I • (Y)، والمقياس الوارد في دراسة مدني (10 • (Y)، حيث تكونت الاستبانة من جزأين كل فقرة لها تعبير عن مستوى استخدام وسائل الإعلام التفاعلي وفق تدرج خماسي من (1 - 0)، علماً بأنه لا توجد درجة كلية على الاستبانة.
والترفيه، وتداخل الثقافات ساهم في ظهور ثقافات دخيلة على المجتمع السعودي، وإقبال الشباب السعودي على مواقع التواصل الاجتماعي واستغناءه عن قراءة الكتب القيمة. يتضح مما سبق وجود شبه ندرة في الدراسات التي تناولت موضوع البحث الحالي في البيئة السعودية، وهذا من شأنه إبراز أهمية إجرائه في ظل غياب يكاد يكون شبه تام ـ في حدود علم الباحثة ـ لمتغيراته

مجتمعة.

\section{فروض البحث}

بناءً على الإطار النظري، وتأسيساً على نتائج الدراسات السابقة، صاغت الباحثة فروض البحث على النحو التالي: - ملي: ا. تختلف نسب توزبع أفراد عينة البحث للمواقع الاجتماعية التفاعلية. Y. يختلف الغرض من استخدام مواقع الإعلام التفاعلي لدى أفراد العينة؟ r. توجد فروق دالة إحصائياً في درجة استخدام وسائل الإعلام التفاعلي لدى أفراد العينة تبعاً للتخصص الدراسي (علمي - أدبي). ع. توجد فروق دالة إحصائياً في درجة استخدام وسائل الإعلام التفاعلي لدى أفراد العينة تبعاً للمستوى التعليمي للوالدين (منخفض - متوسط مرتفع). ه. توجد فروق دالة إحصائياً في درجة استخدام وسائل الإعلام التفاعلي لدى أفراد العينة تبعاً لمستوى دخل الأسرة (منخفض - متوسط ـ مرتفع). 


\section{الخصائص السيكومترية للاستبانة:}

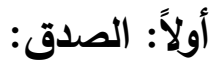

تم حساب الصدق باستخدام صدق المحكمين: حيث تم تحكيم الاستبانة وذلك بعرضها على عدد (9) من الفئ المحكمين المتخصصين في التربية وعلم النفس بكلية التربية بجامعة جدة، وجامعة الطائف، بهدف إبداء الرأي حول مدى تطابق أسئلة الاستبانة مع ما بالفان تقيسه، إلى جانب سلامتها من حيث الصياغة اللغوية والعلمية، وأسفر ذلك عن الإبقاء على جميع الأسئلة بعد تعديلها وفقاً لتوجيهات الدحكمين.

ثانيا: الثبات:

للتحقق من ثبات الاستبانة قامت الباحثة بتطبيق مقياس استخدام وسائل الإعلام التفاعلي على عينة أولية استطلاعية قوامها (.0 طالبة) من طالبات الدبلوم التربوي بجامعة جدة، بطريقة إعادة التطبيق، وبلغ معامل الثبات (NV.)، هي قيمة تعطي الثقة لاستخدام الاستبانة والتقه في النتائج المستخلصة

منها.

\section{نتائج البحث}

نتائج الفرض الأول:

وينص الفرض الأول على أنه: " تختلف نسب الفرض استخدام أفراد عينة البحث لمواقع الإعلام التفاعلي". ولاختبار صحة هذا الفرض تم حساب التكرارات والنسب المئوية لاستجابات أفراد العينة على استبانة استخدام وسائل الإعلام التفاعلي، والجدول (r) التابل يوضح النتائج التي تم التوصل إليها في هذا الصدد:
الجزء الأول: يمثل هذا الجزء استمارة البيانات الديموغرفية وتتناول (الكلية ـ القسم - التخصص التصن (علمي ـ أدبي)، العمر ، الدستوى التعليمي للوالدين (منخفض - متوسط - مرتفع) متوسط الدخل الكلي للأسرة في الشهر (منخفض ـ متوسط ـ مرتفع). الجزء الثاني: يتكون من (^) أسئلة كالتالي:

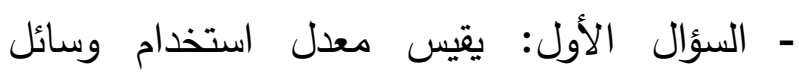
الإعلام التفاعلي لدى أفراد العينة. - الإؤال الثاني: يقيس الغرض من استخدام وسائل الإل العائل الإعلام التفاعلي لدى أفراد العينة. - السؤال الثالث: يقيس متوسط عدد ساعات الإل استخدام وسائل الإعلام التفاعلي في اليوم الواحد

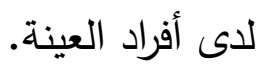
- السؤال الرابع: يقيس عدد المشتركين في الصفحة الخاصة بكل فرد من أفراد العينة. - السؤال الخامس: يقيس عدد الدجموعات المشترك

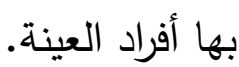
- السؤال السادس: يقيس عدد الزيارات التي يقوم بها أفراد العينة يومياً لمواقع وسائل الإعلام التقاعلي.

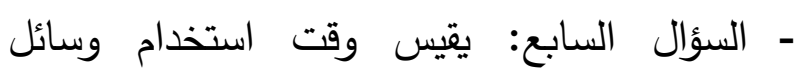
الإعلام التفاعلي لدى أفراد العينة. - السؤال الثامن: يقيس توقع أفراد العينة لاستخدام وسائل الإعلام التقاعلي في المستقبل. 


\section{جدول رقم (1)}

نسب استخدام وسائل الإعلام التفاعلي لاى أفراد العينة

\begin{tabular}{|c|c|c|c|c|c|}
\hline الترتيب & النسب & التكرارات & \multicolumn{2}{|c|}{ عادات الاستخدام } & م \\
\hline 3 & $\% 4.0$ & 8 & يوم واحد شهرياً & \multirow{5}{*}{ معدل الاستخدام } & \multirow{5}{*}{1} \\
\hline 5 & $\% 3.0$ & 6 & يوم واحد كل اسبوعين & & \\
\hline 3 & $\% 4.0$ & 8 & يوم واحد اسبوعياً & & \\
\hline 2 & $\% 6.0$ & 12 & من r-ه أيام أسبوعياً & & \\
\hline 1 & $\% 83.0$ & 166 & 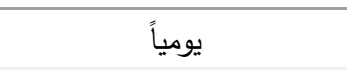 & & \\
\hline 5 & $\% 9.0$ & 18 & أقل من ساعة & \multirow{5}{*}{ عدد ساعات الاستخدام في اليوم الواحد } & \multirow{5}{*}{ r } \\
\hline 3 & $\% 16.0$ & 32 & من ساعة إلى أقل من ساعتين & & \\
\hline 4 & $\% 11.0$ & 22 & من ساعتين إلى أقل من ثلاث & & \\
\hline 2 & $\% 20.5$ & 41 & من ثلاث ساعات إلى أقل من & & \\
\hline 1 & $\% 43.5$ & 87 & خمس ساعات فأكثر & & \\
\hline 4 & $\% 19.0$ & 38 & من · & \multirow{5}{*}{ عدد المشتركين لديك في الصفحة } & \multirow{5}{*}{ r } \\
\hline 2 & $\% 23.0$ & 46 & من .0999 & & \\
\hline 2 & $\% 24.0$ & 48 & من ... & & \\
\hline 5 & $\% 9.0$ & 18 & من $199-199$ & & \\
\hline 1 & $\% 25.0$ & 50 & 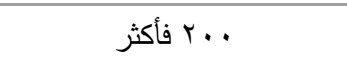 & & \\
\hline 1 & $\% 60.5$ & 121 & 0 & \multirow{5}{*}{ عدد المجموعات التي أنت عضو فيها } & \multirow{5}{*}{$\varepsilon$} \\
\hline 2 & $\% 19.0$ & 38 & ال ا مجموعات & & \\
\hline 3 & $\% 10.5$ & 21 & ا 10 مجموعة & & \\
\hline 4 & $\% 7.0$ & 14 & 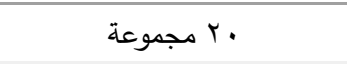 & & \\
\hline 5 & $\% 3.0$ & 6 & أكثر من ·r مجموعة & & \\
\hline 5 & $\% 9.0$ & 18 & 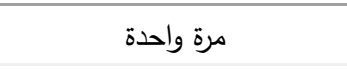 & \multirow{5}{*}{ عدد الزيارات للصفحات المفضلة على الإعلام التفاعلي يوميا } & \multirow{5}{*}{ 。 } \\
\hline 2 & $\% 15.0$ & 30 & مرتان & & \\
\hline 3 & $\% 14.0$ & 28 & ثلاث مرات & & \\
\hline 4 & $\% 9.5$ & 19 & أربع مرات & & \\
\hline 1 & $\% 52.5$ & 105 & خمس مرات فأكثر & & \\
\hline
\end{tabular}


استخدام وسائل الإعلام التفاعلي للى طالبات الدبلوم التربوي بجامعة جدة في ضوء بعض المتغيرات الديموغرافية

\begin{tabular}{|c|c|c|c|c|c|}
\hline 2 & $\% 12.0$ & 24 & في أوقات محددة & \multirow{4}{*}{ موعد استخدام وسائل الإعلام التفاعلي } & \multirow{4}{*}{1} \\
\hline 3 & $\% 7.0$ & 14 & بعد الانتهاء من الاستذكار & & \\
\hline 4 & $\% 2.0$ & 4 & في اجازة نهاية الأسبوع & & \\
\hline 1 & $\% 79.0$ & 158 & في أي وقت & & \\
\hline 4 & $\% 5.0$ & 10 & التوقف عن استخدام وسائل & \multirow{4}{*}{ توقع التعامل مع وسائل الإعلام التفاعلي } & \multirow{4}{*}{ v } \\
\hline 3 & $\% 26.0$ & 52 & الحد من استخدام وسائل & & \\
\hline 1 & $\% 40.5$ & 81 & التقليل من استخدام وسائل & & \\
\hline 2 & $\% 28.5$ & 57 & زيادة استخدام وسائل التواصل & & \\
\hline 3 & $\% 4.0$ & 8 & Facebook & \multirow{5}{*}{ أكثر وسائل الإعلام التفاعلي استخداماً } & \multirow{5}{*}{$\wedge$} \\
\hline 2 & $\% 17.0$ & 34 & Twitter & & \\
\hline 5 & $\% 0$ & 0 & MySpace & & \\
\hline 4 & $\% 3.0$ & 6 & Google+ & & \\
\hline 1 & $\% 76.0$ & 152 & WhatsApp & & \\
\hline
\end{tabular}

- نسبة من يستخدمون وسائل الإعلام التفاعلي في أي وقت هي الأعلى نسبة حيث بلغت (09\%). - نسبة توقع التعامل مع وسائل الإعلام التفاعلي في المستقبل (التقليل من استخدام وسائل الإعلام التفاعلي) هي الأعلى نسبة حيث بلغت ( • ؛ \%). - نسبة أكثر المواقع استخداماً (WhatsApp) هي هي الآي الأعلى نسبة حيث بلغت (\%>7\%). وتثير نسب الاستخدام السابقة إلى الاستعداد الواضح لدى عينة البحث (طالبات الدبلوم التربوي بالجامعة) إلى إدمان استخدام وسائل الإعلام

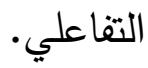

يتضح من الجدول السابق (ب) ما يلي: - نسبة استخدام وسائل الإعلام التفاعلي يومياً هو الأعلى نسبة حيث بلغت (س人م\%). - نسبة عدد ساعات الاستخدام في اليوم الواحد (خمس ساعات فأكثر) هي الأعلى نسبة حيث بلغت . $(\% \leqslant r, 0)$ - نسبة عدد المشتركين في الصفحة ( . . ب فأكثر) هي الأعلى نسبة حيث بلغت (0r\%). - نسبة عد المجموعات المشترك فيها ل

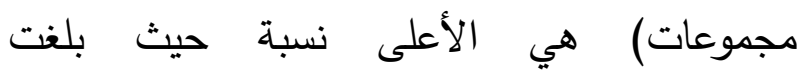
$\cdot(\% 7 \cdot, 0)$ - نسبة عدد الزيارات للصفحات المفضلة على على وسائل الإعلام التفاعلي يومياً أكثر من خمس مرات هي الأعلى نسبة حيث بلغت (0 r,o \%). 

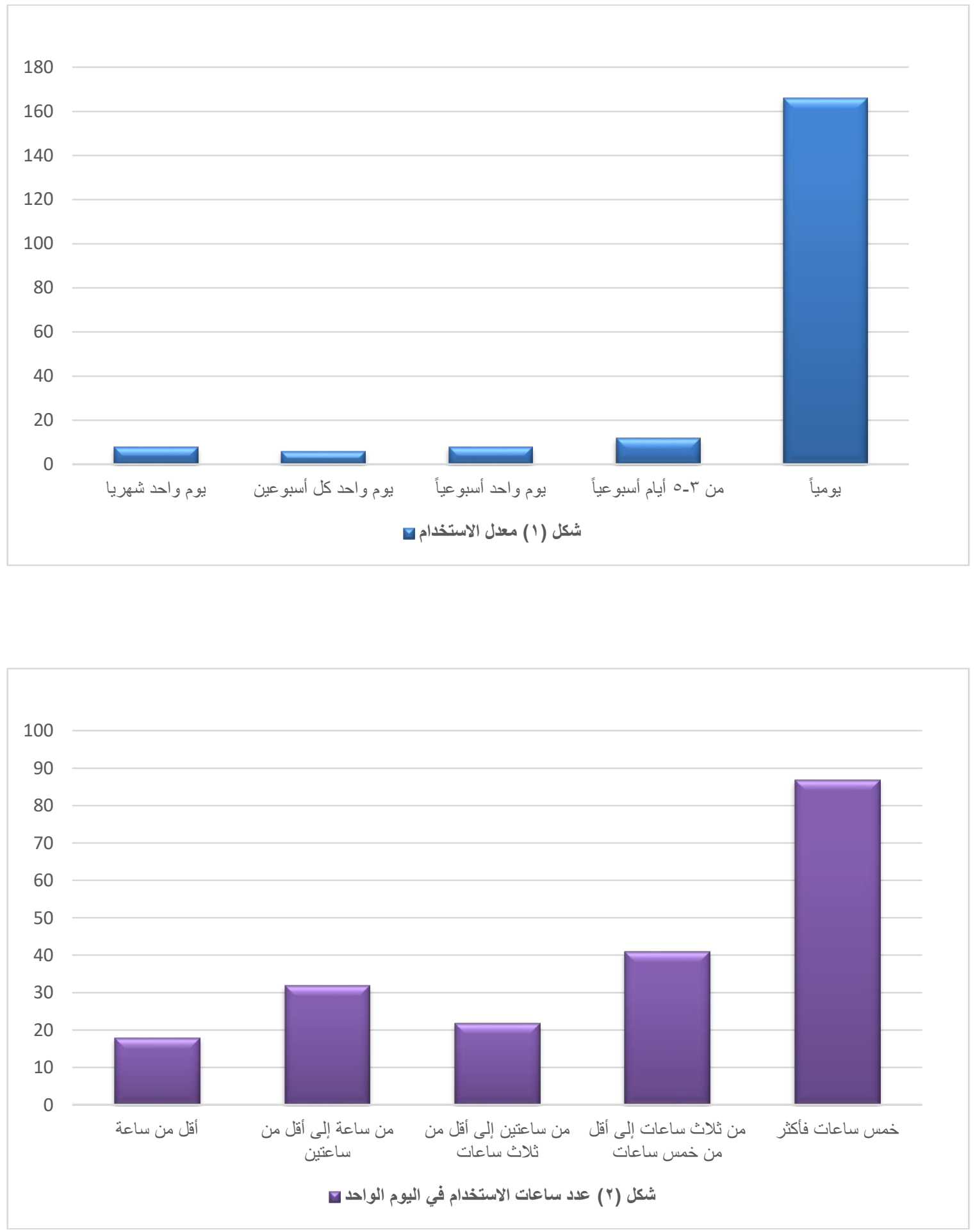

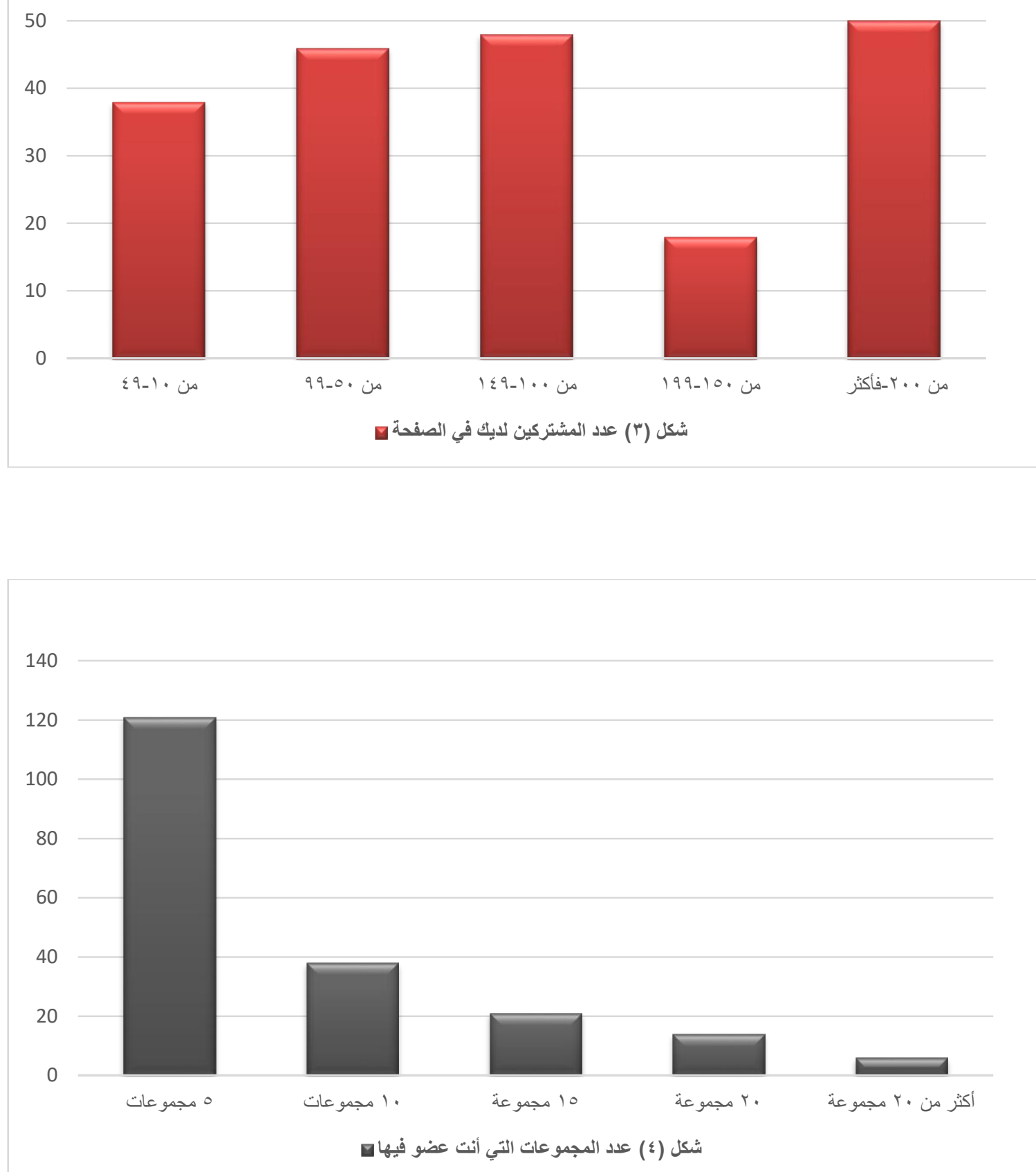

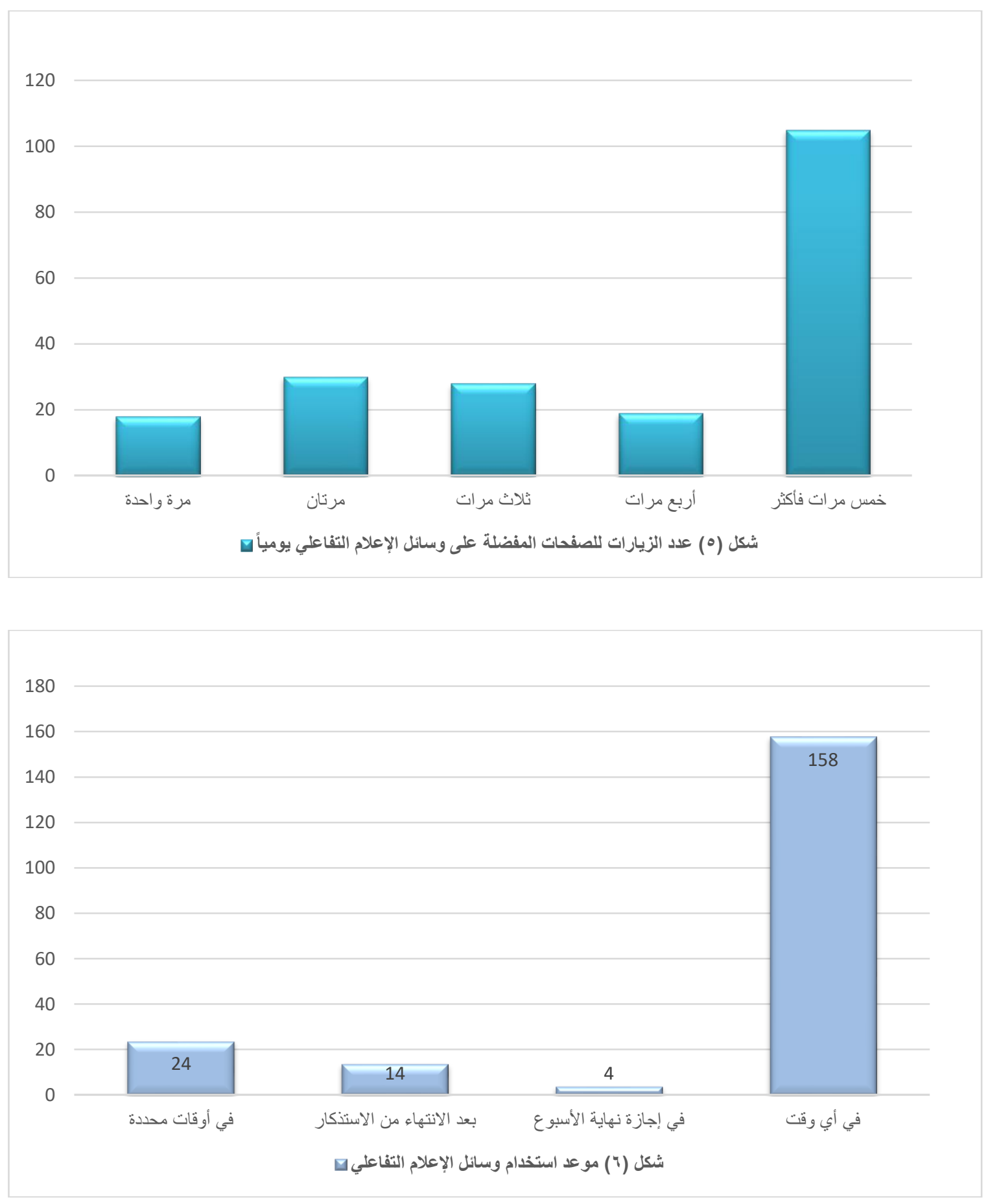
M. استخدام وسائل الإعلام التفاعلي لاى طالبات الدبلوم التربوي بجامعة جدة في ضوء بعض المتغيرات الديموغرافية

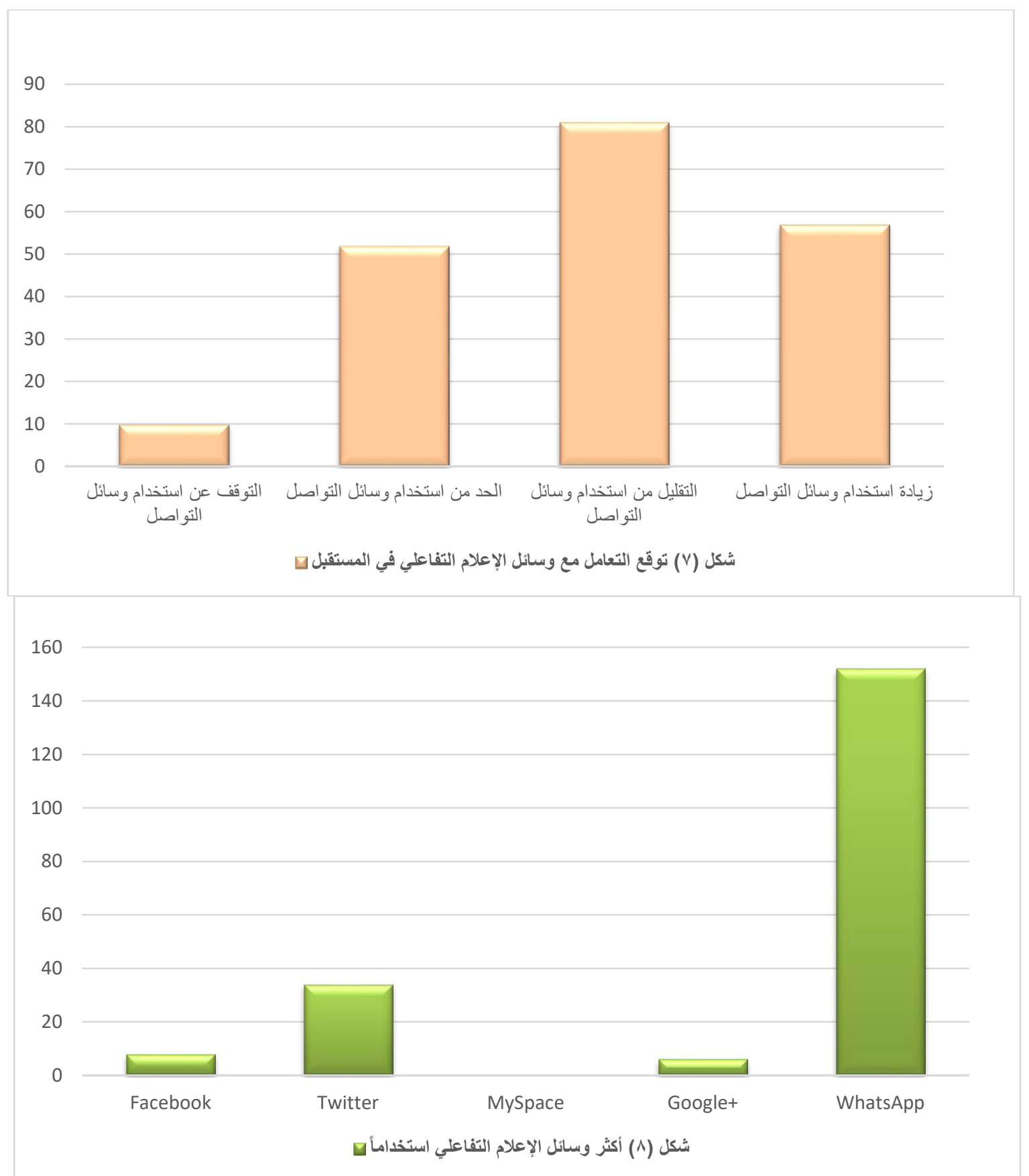

فهو مجتمع يتفاعل في بيئة الكترونية ـ افتراضية ويشترك أعضاؤه في الكثير من الروابط والاهتمامات والأنشطة التفاعلي المشتركة، وقد يكون هناك حضور طبيعي (شخصي) خلف أجهزة الحواسيب،
ويمكن تفسير هذه النتائج في ضوء ما ذكره رحومة

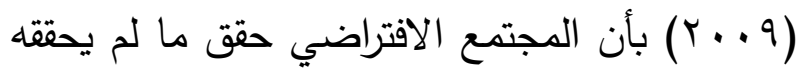
المجتمع الطبيعي بما توفره تكنولوجيا المعلومات والاتصالات من تقنيات وخدمات عالية المستوى، 
الأفراد كلما زادت نسبة اختيارهم لله (المدني،

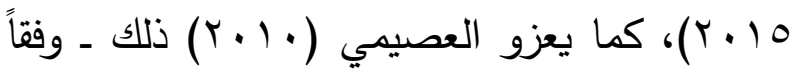
للاتجاه السلوكي - إلى أن المكافآت التي توفرها وسائل التفاعل التفاعلي مختلفة وتحقق إثباعات تتراوح ما بين الإشباعات المعرفية، والعاطفية، والتفاعلي، والترفيهية، هذه المكافآت والاشباعات تشكل سلوك الادمان، ويصبح هذا السلوك نموذجي؛ مما يجعله يعزز هذا السلوك ويكرره، والأدهى من ذلك أن هذا الشعور لا يتغير في نوعه ولكنه يتغير في شدته ويصبح أشد وأشد مما يوقع الفرد في العديد من الاضطرابات السلوكية والنفسية والانفعالية. وتتفق النتيجة التي تشير إلى أن استخدام هي الأعلى نسبة لاى أفراد العينة؛ (WhatsApp)

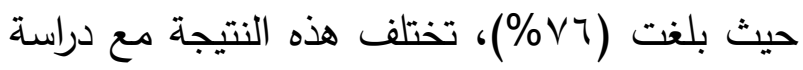
منصور (11 (Y)، والتي توصلت إلى أن موقع احتل الترتيب الأول، يليه موقع (Facebook) حسب نتائج الدراسة. (WhatsApp) نتائج الفرض الثاني: وينص الفرض الثاني على أنه: " يختلف الغرض من استخدام مواقع الإعلام التفاعلي لدى أفراد العينة" ولاختبار صحة هذا الفرض تم حساب التكرارات والنسب المئوية لاستجابات أفراد العينة على استبانة استخدام وسائل الإعلام التفاعلي، والجدول التالي (ع) يوضتح النتائج التي تم التوصل إليها في هذا الصدد:
أو لا يكون ذلك، أي مجرد حضور افتراضيبرامجي، في أوقات معينة، فالبيئة البرمجية للتفاعل تتقاسم أنماطاً متتوعة للتفاعل وأحجاماً صغيرة أو كبيرة من المشاركين وفترات زمنية غير مقيدة كل ذلك يتيحه الفضاء السيبيري بدلاً من الفضاء الطبيعي، فتتفاعل جماعات النقاش والحوار ويحدث التآلف وتتمو المصالح الشخصية التفاعلي والاهتمامات النفسية والثقافية والسياسية والاقتصادية والأدبية المشتركة إلى جانب كون المجتمعات الافتراضية هي عملياً جماعات لتبادل المعلومات والاتصال التقني المفيد معرفياً واجتماعياً، والذي بدوره يكتسب نوعاً من العادات والتقاليد واللوائح التفاعلي المشتركة من الجماعة أو المجتمع الافتراضي المعني. كما تتقق هذه النتيجة مع مدخل الاستخدامات والإشباعات الإلكترونية التي أصبحت لغة العصر من ناحية، وجود انتقائية في اختيار الجمهور لوسيلة اتصالية معينة والتعرض لمضمون معين فيها، ويعنى مدخل الاستخدامات والإشباعات في الأساس بجمهور الوسيلة الإعلامية التي تشبع رغباته وتلبي حاجاته الكامنة في داخله، ومعنى ذلك أن الجمهور ليس سلبياً يقبل كل ما تعرضهه عليه وسائل الإعلام، بل يمتلك غاية محددة من تعرضها يسعى إلى تحقيقها، فأعضاء الجمهور هنا بدرجة ما باحثون نشطون عن المضمون الذي يبدو أكثر إثباعا لهم، وكلما كان مضمون معين قادراً على تلبية احتياجات 
جدول رقم (r)

الغرض من استخدام وسائل الإعلام التفاعلي لدى أفراد العينة

\begin{tabular}{|c|c|c|c|c|}
\hline الترتيب & النسبة النوية & التكرارات & الغرض من الاستخدام & p \\
\hline 5 & $10.5 \%$ & 21 & استخدم مواقع الاعلام التفاعلي لأغراض الدراسة & 1 \\
\hline 9 & $4 \%$ & 8 & تخفق وسائل الإعلام التفاعلي عني ضغوط & $r$ \\
\hline 3 & $12 \%$ & 24 & الأنشطة الثقافية والرياضية والإعلام التفاعلي من متابعة التصائية & r \\
\hline 8 & $7.5 \%$ & 15 & تمكني وسائل الإعلام التقاعلي من التعرف على & $\varepsilon$ \\
\hline 10 & $3 \%$ & 6 & تكسبني وسائل الإعلام التفاعلي مهارات الحوار & o \\
\hline 6 & $9.5 \%$ & 19 & تقلل وسائل الإعلام التفاعلي شعوري بالوحدة & 7 \\
\hline 1 & $19 \%$ & 38 & 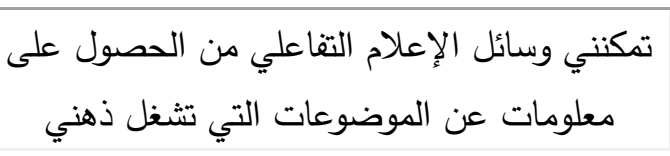 & $v$ \\
\hline 2 & $14.5 \%$ & 29 & تُعد وسائل الإعلام التفاعلي وسيلة جيدة للتسلية & $\wedge$ \\
\hline 4 & $11.5 \%$ & 23 & $\begin{array}{c}\text { أتواصل من خلال وسائل الإعلام التفاعلي } \\
\text { بالأهل والأصدقاء }\end{array}$ & 9 \\
\hline 7 & $8.5 \%$ & 17 & 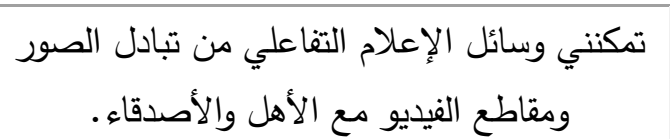 & 1. \\
\hline
\end{tabular}




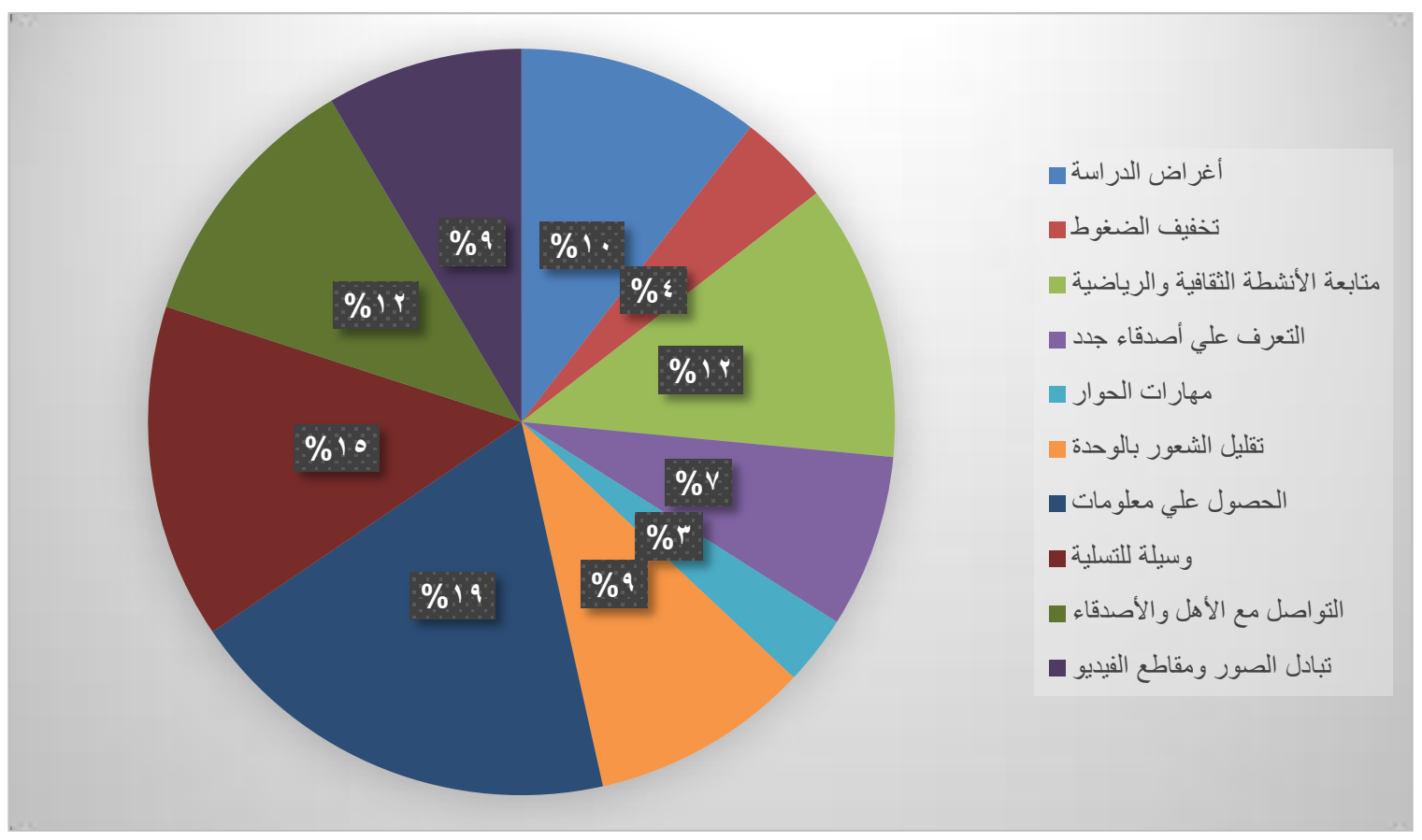

شكل (9) موعل (a)

(الغرض من استخدام وسائل الإعلام التفاعلي لاى العينة)

تثير النتائج في الجدول السابق (r) إلى حصول طلب الرخصة للحصول على تلك المعلومة وفي أي

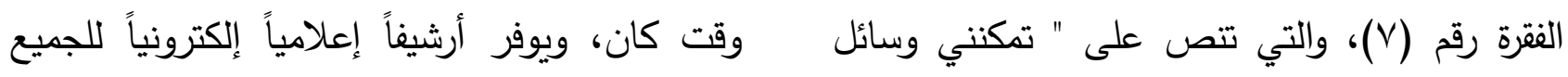
الإعلام التفاعلي من الحصول على معلومات عن دون قيود، حيث أصبحت وسائل الإعلام التفاعلي الموضوعات التي تشغل ذهني" على أعلى تكرار، محور الحياة المعاصرة لما له أهميه كبيرة باحتواء

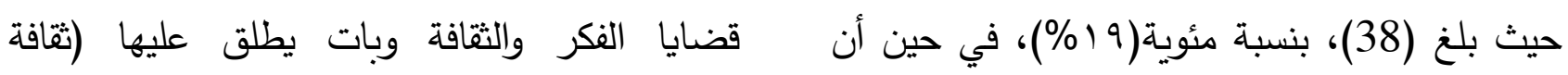

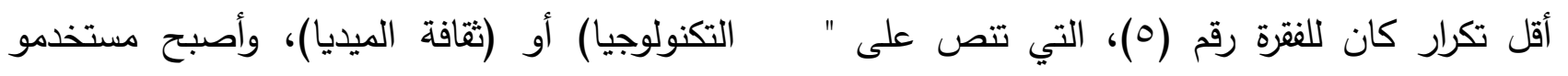

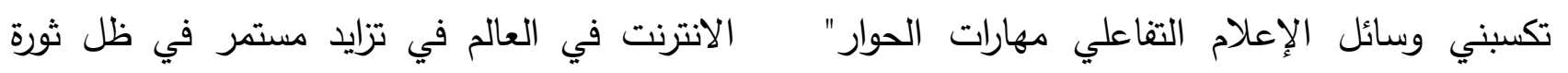

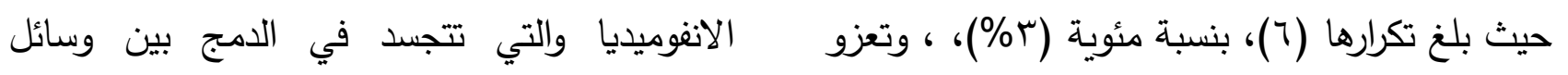

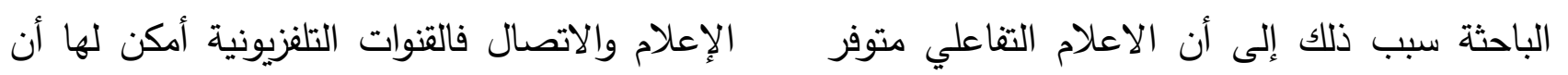
دائما إذ يمكن للفرد أن يحصل على أية معلومة تم تبث إلث برامجها عبر الموبايل؛ وبذلك استطاع الإعلام

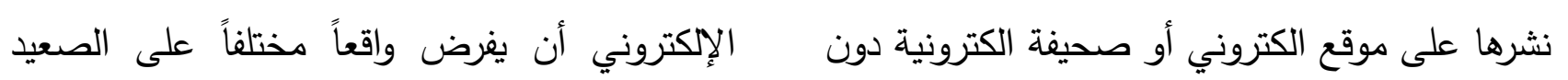


والخلفيات والمعلومات الأساسية والتحليلات ومقالات

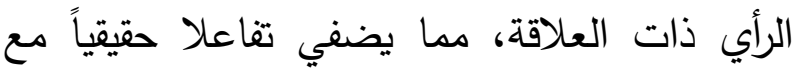
المواد الإعلامية، كما يؤيد ذلك ما ذكره شفيق

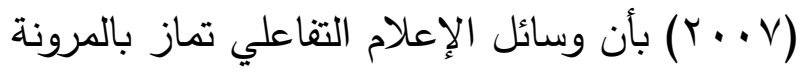
من الناحية التقنية، أما على المستومى الإعلى الإعلامي

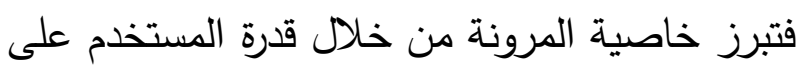
الوصول بسهولة إلى عدد كبير من مصادر المعلومات والمواقع وهذا ما يتيح له فرصة انتقاء

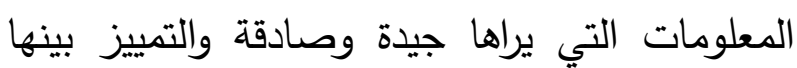
وبين المواقع التي تقدم معطيات مزيفة مع العلم أن يراهات

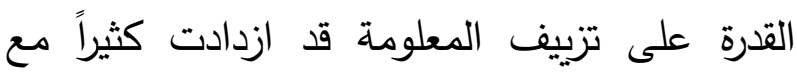
ظهور الانترنت الذي سهل كثيراً من عمليات تركيب الصور وتعديل الأصوات وغيرها.

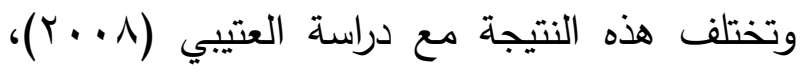
والتي أشارت نتائجها إلى تمضية الوقت والتسلية كان دران التهيل الدافع الأول لاستخدام وسائل الإعلام التفاعلي، كما

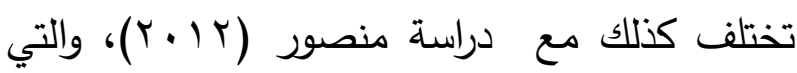
توصلت إلى أن التواصل مع الآخرين يمثل المرتبة الأولى في الغرض من استخدام وسائل الإعلام التفاعلي لاى عينة الدراسة. وخلاصة القول إن وسائل الإعلام التفاعلي توفر حصيلة للمعرفة البشرية على مدى العصور وهي إنيا متاحة لجميع الناس للاستفادة منها، وطريقة مدئة استعمالها سهلة باستخدام محرّكات البحث المختلفة والعديدة، وقبل أخذ وتداول المعلومات يجب التأكد من مصدرها لأنّ هذه الثبكة تعتبر مصدراً مفتوحاً
الإعلامي والثقافي والفكري والسياسي، فهو لا يعد تطويراً فقط لوسائل الإعلام التقليدية وإنما هو وسيلة إعلامية احتوت كل ما سبقها من وسائل الاعلام، من خلال انتشار المواقع والمدونات الإكترونية وظهور الصحف والمجلات الاككترونية التي تصدر عبر الانترنت، بل إن الدمج بين كل هذه الأنماط

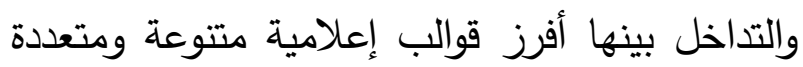
بما لا يمكن حصره أو التنبؤ بإمكانياته، فالعصر الحالي يعد بحق عصر الإعلام الإكتروني، إعلام

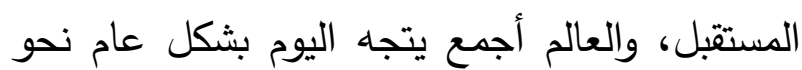

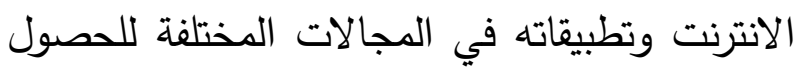

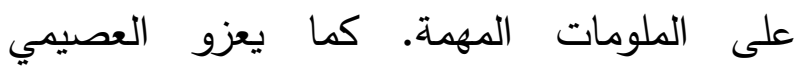

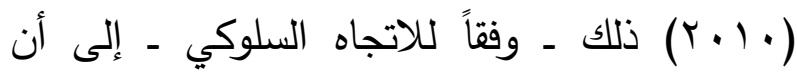
المكافآت التي توفرها وسائل التفاعل التفاعلي مختلفة وتحقق إشباعات تتراوح ما بين الإشباعات المعرفية،

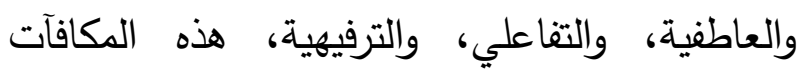

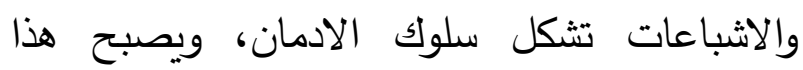
السلوك نموذجي؛ مما يجعله يعزز هذا السلوك

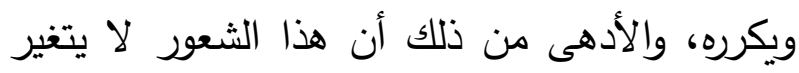
في نوعه ولكنه يتغير في شدته ويصبح أثند وأثد مما يوقع الفرد في العديد من الاضطرابات السلوكية والنفسية والانفعالية. كما أن وساءل الإعلام التفاعلي تتميز بالتحديث إذ يتم تحديث وتجديد الأخبار

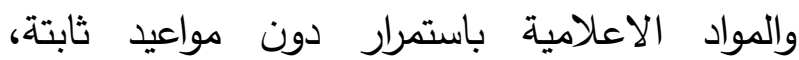
فالمحتوى الإعلامي الإلكتروني يتمتع بالسبق والقدرة

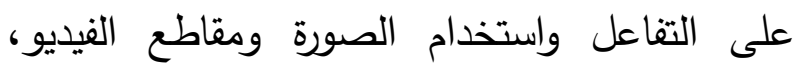


أن طالبات مرحلة الدبلوم قد اكتسبن مهارات الحوار خلال المراحل الدراسية السابقة ومن خلا أيضاً التشئة الاجتماعية وتشكلت لديهن مهارات الحوار وبالتالي سيكون تأثير وسائل الإعلام التفاعلي

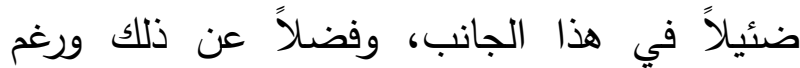
إيجابيات شبكة التواصل الاجتماعي إلا أن لها تأثيراً

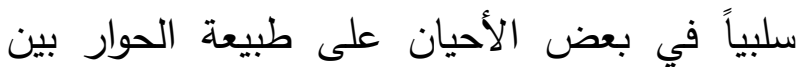
أفراد المجتمع فقد تكون سبياً مباشراً في الانقسام المجتعي، ونشر الثائعات، وتدني مستوى ثقافة

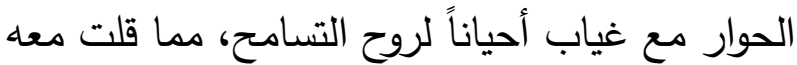
فرص التوافق والتواصل الهادف. نتائج الفرض الثالث:

وينص الفرض الثالث على أنه "توجد فروق دالة إحصائياً في استخدام الطالبات أفراد العينة لوسائل الإعلام التفاعلي تبعا للمستوي التعليمي للوالدين".

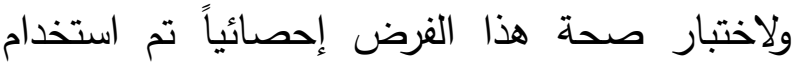
تحليل التباين أحادي الاتجاه لمعرفة الفروق بين متوسطات درجات أفراد عينة البحث في استخدام وسائل الإعلام التفاعلي تبعاً لاختلاف المستوي

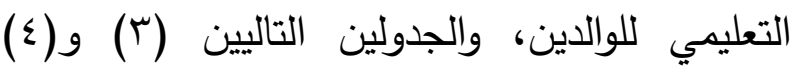
يوضحان نتائج التحليل الاحصائي في هذا الصدد: ـ أولاً: المستوي التعليمي للأب:
للمعلومات. تقدم معلومات تشمل جميع نواحي الحياة مثل المعلومات الصحية، والثقافية، والأشغال اليدوية، والمعلومات الجغرافية والتاريخية، ومهارات

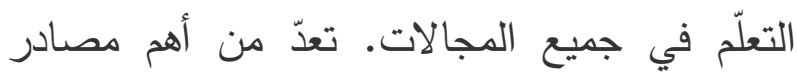
الحصول على المعلومات التجارية عن الكنتجات حسب أنواعها، إذا كان منتج صناعي، أو تقني، أو استهلاكي، كما يمكن الحصول على الملفات التي نحتاجها لإتمام بحث، أو مشروع تخرّج، ويمكن

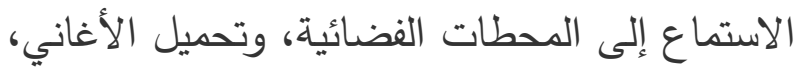
ومقاطع الفيديو، ومتابعة بث القنوات الفضائية. ايصال الأخبار على مدار الساعة، وإمكانية متابعة

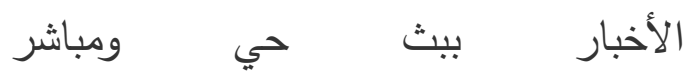
.(https://mawdoo3.com) كما يسجل لهذه الشبكات التفاعلية كسر احتكار المعلومة فبدأت تتجمع وتتحاور بعض التكتلات والأفراد داخل هذه الشبكات تحمل أفكاراً ورؤيً

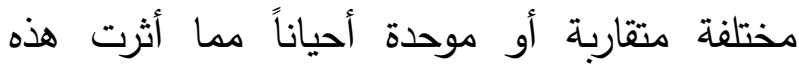
الحوارات على تلك الثبكات وزادتها غنيً وجعلت من الصعب جداً على الرقابة الوصول إليها أو السيطرة وجطي عليها أو لجمها في حدود معينة. أما بالنسبة للنتيجة التي تشير إلى حصولى مصله الفئرة التي تتص على " تكسبني وسائل الإعلام التفاعلي

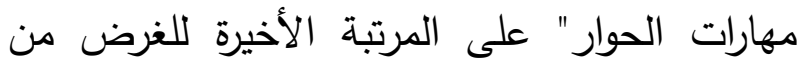
استخدام وسائل الإعلام التفاعلي فقد يعود ذلك إلى 
جدول (r)

تحليل التباين لاستخدام أفراد عينة البحث لوسائل الإعلام التفاعلي

تبعاً للمستوي التعليمي للأب (أمي ـ تعليم عام ـ تعليم عال).

\begin{tabular}{|c|c|c|c|c|c|}
\hline مستوى الدلالة & ق " " & المتوسطات & الحرية & المربعات & مصدر التباين \\
\hline \multirow{3}{*}{.401} & \multirow{3}{*}{.917} & 22.008 & 2 & 44.016 & بين المجموعات \\
\hline & & 23.990 & 197 & 4725.979 & داخل المجموعات \\
\hline & & & 199 & 4769.995 & الكلي \\
\hline
\end{tabular}

يتضح من الجدول السابق (r) عدم وجود فروق دالة ـ ثانياً: المستوي التعليمي للأم: إحصائياً بين أفراد العينة في استخدام وسائل الإعلام التفاعلي باختلاف مستوى تعليم الأب.

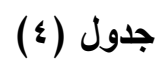

تحليل التباين لاستخدام أفراد عينة البحث لوسائل وسائل الإعلام التفاعلي تبعاً للمستوي التعليمي للأم (أمي ـ تعليم عام ـ تعليم عال).

\begin{tabular}{|c|c|c|c|c|c|}
\hline مستوى & قيمة " ف " & المتوسطات & الدرية & المربعات & مصدر التباين \\
\hline \multirow{3}{*}{.374} & \multirow{3}{*}{1.045} & 25.034 & 3 & 75.101 & بين المجموعات \\
\hline & & 23.954 & 196 & $\begin{array}{c}4694.89 \\
4\end{array}$ & المجموعات \\
\hline & & & 199 & $\begin{array}{c}4769.99 \\
5\end{array}$ & الكلي \\
\hline
\end{tabular}

يتضح من الجدول السابق (ع) عدم وجود فروق دالة ويمكن تفسير هذه النتيجة في إطار المحددات

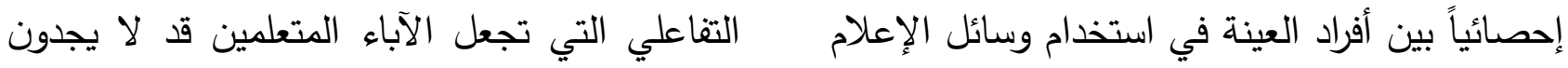

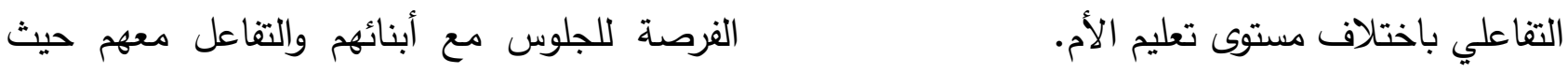
يكونون عادة في حالة من الانشغال الدائم 
يحقق لأفرادها إشباع حاجاتهم باعتبارهم مكونات في هذه المنظومة يتفاعلون مع بعضهم ويكمل كل منهم الآخر ، ويتحقق ذلك من خلال علاقات أسرية وأدوار واضحة بالإضافة إلى الدفء والعاطفة من خلال التعبير عن المشاعر والوجدان بين الآباء والأبناء وبالتالي يقل هروبهم إلى العالم الافتراضي. وخلاصة القول إن هناك إهمالاً أسرياً واضحاً في القاضي تربية الأبناء على نطاق واسع في مجتمعنا، فجهود الوالدين غالباً ما تركز على توفير المتطليات فلئل المادية، متتاسين حاجة أبنائهم إلى الدب والأبواء

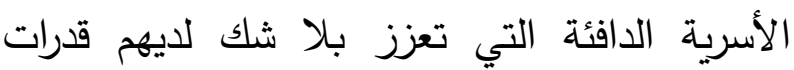
عديدة منها الرضا بالواقع وعدم الهروب إلى العالم

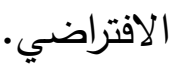
وتختلف هذه النتيجة مع دراسة لخريف والعنزي، (د. ت) التي أشارت أنه كلما ارتقى المستوى التعليمي داني

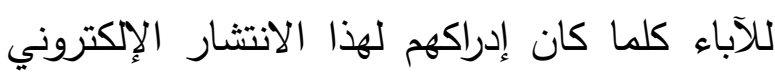

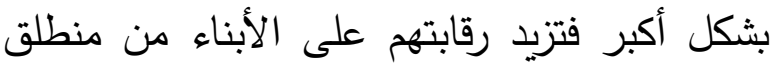

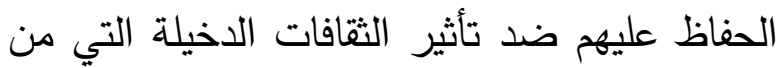
شأنها التأثير بالسلب على هويتهم الدينية والتفاعلي. نتائج الفرض الرابع:

وينص الفرض الرابع على أنه " توجد فروق دالة إحصائياً في استخدام الطالبات أفراد العينة لوسائل العائل الإعلام التفاعلي تبعاً لمستوى دخل الأسرة".

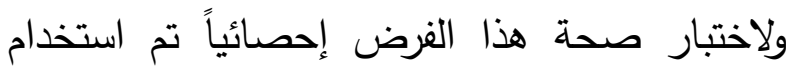
تحليل التباين أحادي الاتجاه لمعرفة الفروق بين متوسطات درجات أفراد عينة البحث في استخدام
بطموحاتهم الثخصية وقيامهم بالعديد من المهام والأعمال الذهنية التي تستحوذ في الغالب على نلى اهتماماتهم الثخصية. وتعتقد الباحثة من خلال النتائج السابقة أن المشكلة أكبر من مجرد التعليم أو مستواه، فالتغييرات الكبيرة

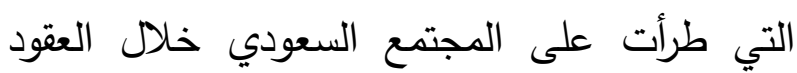

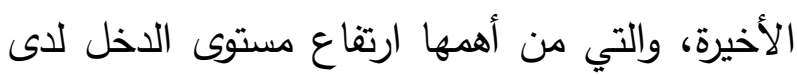
الفرد، وخروج الأم إلى ميدان العمل، والذي أدى الثى الثي بدوره على الاعتماد على الخدم في تربية الأبناء، فالأم العاملة قد لا تجد الوقت الكافي لتبادل الحديث والمناقثة مع الأبناء وما قد يصاحب ذلك من نتائج نفسية، وسلوكية خطيرة.

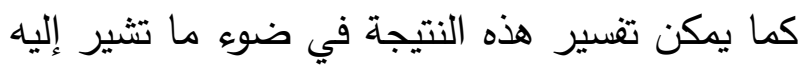

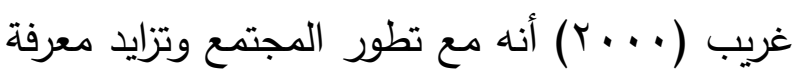
الإنسان والتقدم الصناعي والتكنولوجي ومنجزات التان الثورة الاتصالية حدث إرباك هائل في أساليب اتصال الأفراد في المجتمع وداخل الأسرة، فمثلاً مع التعالئ ظهور وسائل الاتصالات الحديثة الكمبيوتر والتلفزيون انخف معدل الأحاديث الأسرية، وأصبح عمل الوالدين وانثغال الأبناء وازدياد مصادر الأدياد المعلومات و والترفيه، وازدياد الضغوط التانياء التفاعلي والمادية والنفسية عوامل تدفع أفراد الأسرة لكي يكون لكل منهم عالمه الخاص الذي قد لا يتاح للآخرين

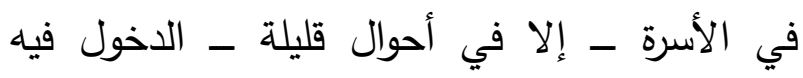
ومشاركته هذا العالم، في حين يتمثل الهذف الأساسي للأسرة كمنظومة في توفير مناخ منتج 
وسائل الإعلام التفاعلي تبعاً لاختلاف مستوى دخل الإحصائي في هذا الصدد: الأسرة، والجدول التالي (0) يوضح نتائج التحليل

(0) جدول

تحليل التباين لاستخدام أفراد عينة البحث لوسائل وسائل الإعلام التفاعلي

تبعاً لمستوى الاخل (منخفض ـ متوسط ـ مرتفع)

\begin{tabular}{|c|c|c|c|c|c|}
\hline مستوى الدلاية & قيمة " ف" & المتوسطات & الحربة & المربعات & مصدر التباين \\
\hline \multirow{3}{*}{0.130} & \multirow{3}{*}{2.520} & 58.175 & 5 & 290.873 & بين المجموعات \\
\hline & & 23.088 & 194 & 4479.122 & داخل المجموعات \\
\hline & & & 199 & 4769.995 & الكلي \\
\hline
\end{tabular}

بالمقارنة بذوي الدخل المرتفع ، ربما يفسر ذلك بانشغال الأسر ذات الاخل المنخفض بمحاولة الارتقاء بمستوى الاخل مما يجعلهم في غفلة عن المراقبة للأبناء، وفي المقابل فإن الأسر ذات الدخل المرتفع يراقبون أبنائهم بشكل دائم عن الأسر ذات الدخل المنخفض، وهذه الرقابة من شأنها التقليل من التأثير السلبي لتلك الوسائل التفاعلي.

\section{الخاتمة}

يعدالفضاء المعلوماتي بكل أبعاده مساحة واسعة لنقل الثقافات بين الأمم والشعوب، وإن الباحثة ومن خلال هذا البحث المختصر لتضع الأهمية القصوى في توجيه الأبناء والطلاب والطالبات نحو الاستخدام الأمثل لمواقع التفاعل التفاعلي، وبث الرقابة الذاتية على مستوى الأسر والمؤسسات التربوية.
يتضح من الجدول السابق (0) عدم وجود فروق دالة إحصائياً بين أفراد العينة في استخدام وسائل الإعلام التفاعلي باختلاف مستوى دخل الأسرة، وقد يعود ذلك إلى أن أجهزة الحاسب الآلي أصبحت بأسعار معقولة، مع سهولة الوصول إلى شبكة الإنترنت في جميع المستويات الاقتصادية، لا سيما مع الانخفاض المستمر في كلفـة الاشتراك بشبكة الإنترنت. وهذه النتيجة تختلف عن نتائج دراسة حنفي (س . . r) التي أوضحت أن الأسر متوسطة المستوى الاقتصادي هي الأكثر استخداماً لوسائل الإعلام التفاعلي، كما تختلف عن دراسة الخريف والعنزي (د. ت) والتي توصلت إلى وجود فروق باختلاف مستوى الدخل الشهري لصالح الدخل المرتفع، فعند انخفاض دخل الأسرة تندر مراقبة الآباء للأبناء بنسبة كبيرة 
رسالة ماجستير (غير منشورة)، جامعة الأزهر، غزه. - البلوشي، حسين (111) الإ): أثر مواقع وسائل

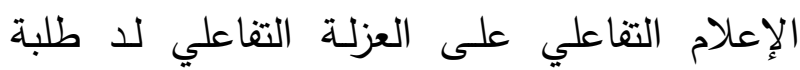
الكويت المغتربين في جمهورية مصر العربية. رسالة ماجستير (غير منشورة)، جامعة ب أكتوبر، مصر

- ابو خطوة، السيد عبد المولى؛ الباز؛ أحمد

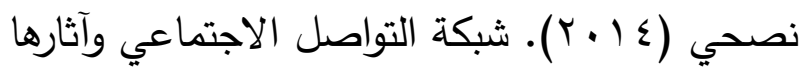
على الأمن الفكري لاى طلبة التعليم الجامعي بمملكة

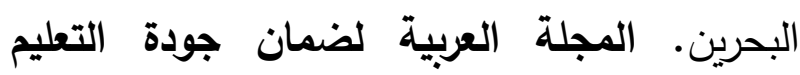

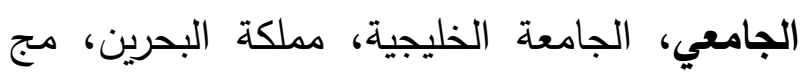
(Y)

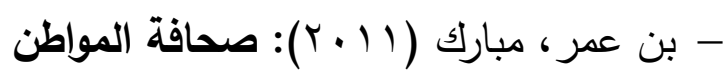

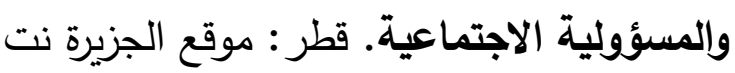

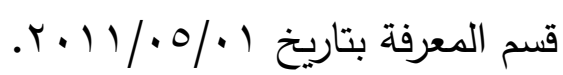

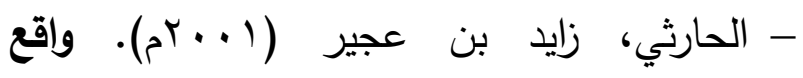
المسؤولية الثخصية الاجتماعية لاى الثباب السعودي وسبل تنميتها، الرياض: مركز الدراسات

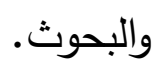

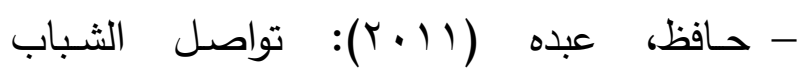
الجامعي من خلال المواقع التفاعلي. المؤتمر العلمي - وسائل الإعلام أدوات تعبير وتغيير- قسم الصحافة والإعلام، جامعة البترا، عمان.
وفي ضوء نتائج البحث توصي الباحثة بما يلي:

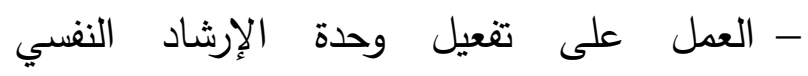
والأكاديمي في الجامعة لإرشاد الطالبات وتوجيهيهن الإنيان نحو الاستخدام الأمثل لوسائل وسائل الإعلام التفاعلي. - ضرورة زيادة الرقابة على مواقع وسائل الإعلام التفاعلي. - ضرورة اهتمام المرشدين الأكاديميين بالتوعية بالآثار الايجابية والسلبية لمواقع وسائل الإعلام

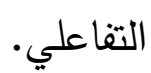
- إجراء المزيد من البحوث التي تلقي الضوء عل خطورة مواقع التوصل التفاعلي من حيث إدمان التران مواقع التفاعل التفاعلي (أعراضه وأسبابه وطرق علاجه) وتأثيره على بناء الشخصية. - بناء برنامج إرشادي متكامل لتنمية المسؤولية الاجتماعية لاى طالبات الجامعة. - القيام بإجراء بحوث مشابهة لهذا البحث، على لإئل شرائح المجتمع المختلفة، وبيان الآثار السلبية والإيجابية الكترتبة على استخدامات هذه الثرائح لمواقع التفاعل التفاعلي المختلفة. المراجع

أولاً: المراجع العربية: - أبو زيد، طاهر حسن (r/ البح): دور وسائل الإعلام التفاعلي في توجيه الرأي العام الفلسطيني وأثرها على المشاركة السياسية (دراسة ميدانية). 
rr.

- خليل، محمد المري (عـ ـ ب): الرضا عن الحياة

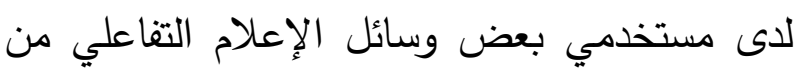
طلبة كلية التربية ـ جامعة الزقازيق - بحث مقدم للمؤتمر العلمي السابع (الدولي الرابع) التعليم وثثقافة وسائل الإعلام التفاعلي، المنعقد في سوهاج

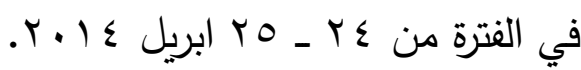
- خوج، حنان أسعد (؟1 (ب): الإسهام النسبي للقبول/الرفض الوالدي في التنبؤ بالمسؤولية الاجتماعية لدى طالبات لرحلة المتوسطة بالمملكة

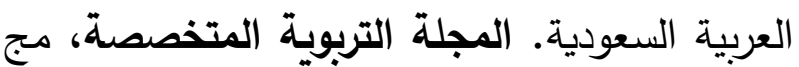

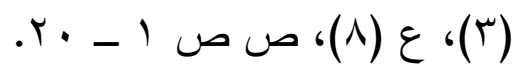

- الدوسري، سامي عبد الرحمن؛ والعريشي، جبريل

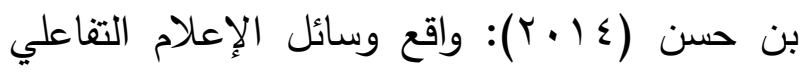
للى طلاب وطالبات الجامعة بالمملكة العربية السعودية. مجلة مكتبة الملك فها الوطنية، مج (Y.)

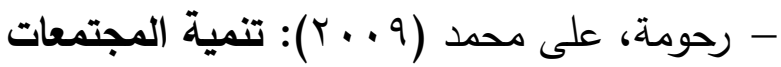
الافتراضية عوامل نجاح جديدة للتطوير الثبكي

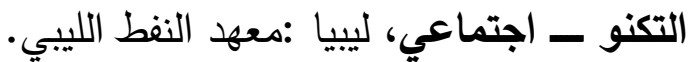

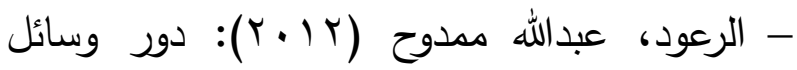
الإعلام التفاعلي في التغيير السياسي في تونس و مصر من وجهة نظر الصحفيين الاردنيين، رسالة ماجستير (غير منشورة)، كلية الإعلام، جامعة

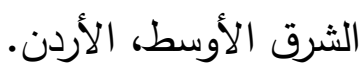

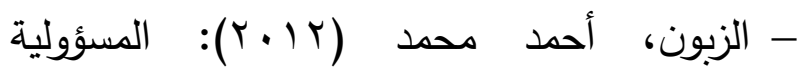
الاجتماعية وعلاقتها بمنظومة القيم الممارسة لدى
- حبيب، راكان عبد الكريخ (19 (ب): وسائل الاتصال والإعلام الجديد. (طץ)، السعودية: مكتبة

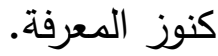

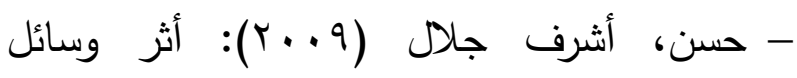
العلاقات التفاعلي بالإنترنت ورسائل الفضائيات على التى العلاقات التفاعلي والاتصالية للأسرة المصرية والقطرية، المؤتمر العلمي السنوي الثالث المؤتمر العلمي السنوي الخامس عشر "الإعلام والأسرة وتحديات العصر"، كلية الإعلام، جامعة القاهرة،

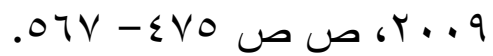
- حسين، منصور (11) (ب): الاعلام الجديد تصريح الأستاذ عبد الله باهمام. السعودية: جريدة الاعلية

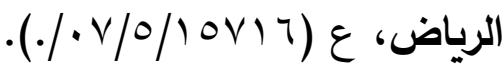

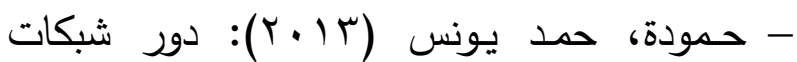
التواصل الاجتماعي في تنمية مشاركة الثباب الفلسطيني في القضايا المجتمعية. رسالة ماجستير (غير منشورة)، المنظمة العربية للتربية والثقافة والعلوم معهد البحوث والدراسات العربية

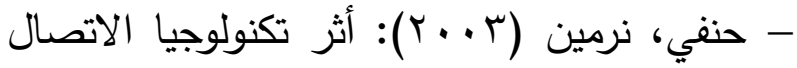

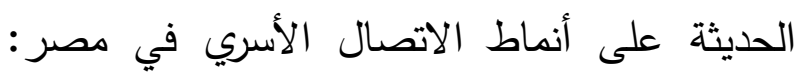

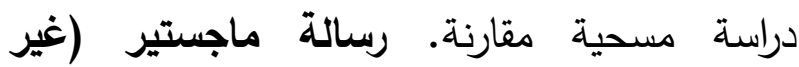
منشورة)، قسم الإعلام وثقافة الطفل. معهذ الدراسات العليا للطفولة. جامعة عين شمس.

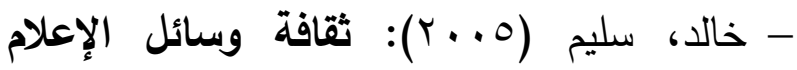
التفاعلي والمجتمعات المحلية. دار المتتبي للنشر والتوزيع: قطر . 
دراسة تطبيقية، رسالة ماجستير (غير منشورة)، جامعة الملك سعود، كلية الآداب، قسم الإعلام.

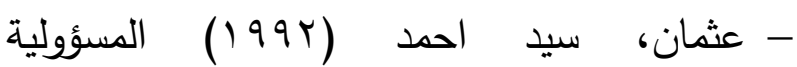
الاجتماعية ، دراسة نفسية اجتماعية، مجلة الكات

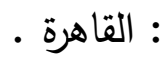

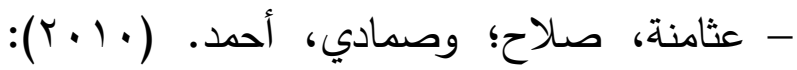
المسؤولية الاجتماعية لاى طلبة الجامعات الأردنية. ورقة عمل مقدمة للمؤتمر الدولي للتعليم العالي لإئي

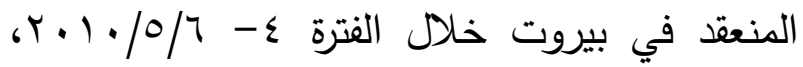

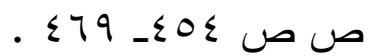
- عثمان، سيد أحمد (917): المسؤولية الاجتماعية والثخصية المسلمة ــ دراسة نفسية تربوية -ـ، القاهرة: مكتبة الأنجلو المصرية. - عثمان، سيد أحمد (1991). المسؤولية الاجتماعية، دراسة نفسية - اجتماعية، مقياس المسؤولية الاجتماعية واستعمالاته، (ط ץ)، القاهرة: مكتبة الأنجلو المصرية. - عثمان، سيد أحمد (•(ب) - التهليل الأخلاقي

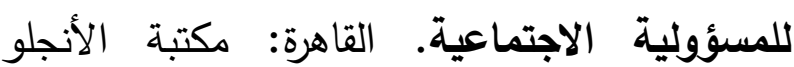

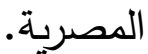

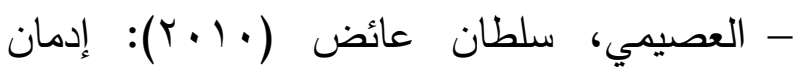
الإنترنت وعلاقته بالتوافق النفسي التفاعلي لاى لإن طلاب المرحلة الثانوية بمدينة الرياض. رسالة ماجستير غير (منشورة)، كلية الدراسات العليا: جامعة نايف العربية للعلوم الأمنية.
طلبة جامعة البلقاء التطبيقية. المجلة الأردنية في العلوم التفاعلي، الأردن، مج (0)، ع (r)، ص ص صله

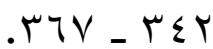

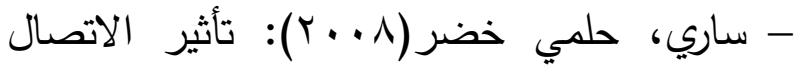
عبر الإنترنت في العلاقات التفاعلي "دراسة ميدانية في المجتمع القطري". مجلة جامعة دمثق، مج الإترني (Y)

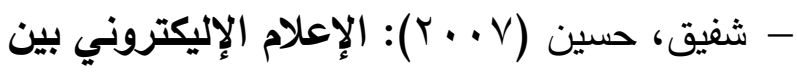
التفاعلية والرقمية. القاهرة: دار رحمة برس للطباعة الإعلاعين

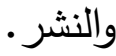

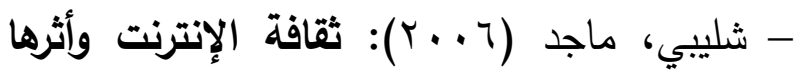

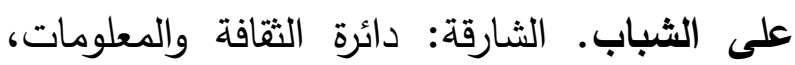

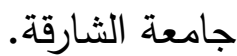

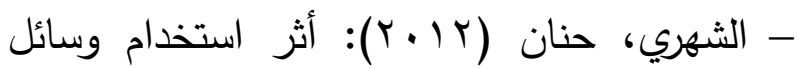
التواصل الإكترونية على العلاقات التفاعلية، رسالة

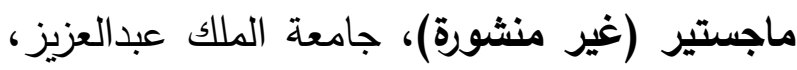

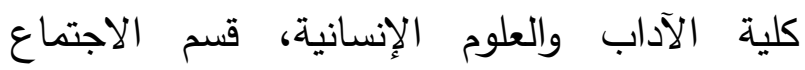
والخدمة التقاعلي.

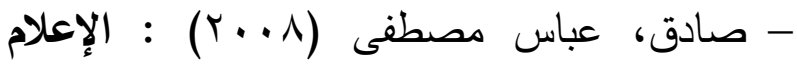
الجديد المفاهيم والوسائل والتطبيقات، مكتبة

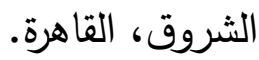
- طاحون، حسين (999(1): تمية المسؤولية الاجتماعية (دراسة تجريبية). رسالة دكتوراه (غير منشورة)، كلية التربية، جامعة عين شمس.

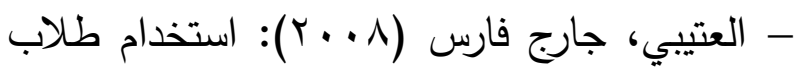
وطالبات الجامعات السعودية شبكة الفيس بوك، 
وعلاقتها بالجو الأسري العام "دراسة تجربيه". رسالة دكتوراه (غير منشورة)، جامعة عين شمس.

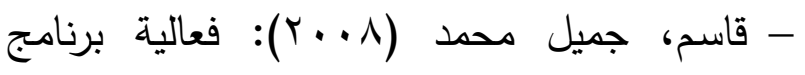

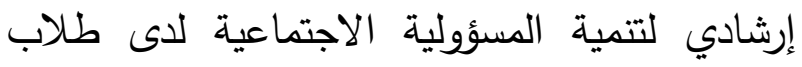
المرحلة الثانوية، رسالة ماجستير (غير منشورة)، كلية التربية، غزة، الجامعة الإسلامية.

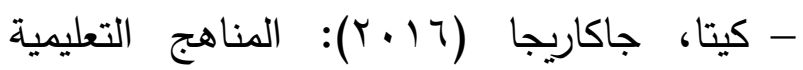
ودورها في تعزيز المسؤلية الاجتماعية لدى طلبة التعليم العالي. مجلة العلوم النفسية والتربوية، جامعة الثهيد حمة لخضر، الوادي، الجزائر، مج مجائه

$$
\text { (r) }
$$

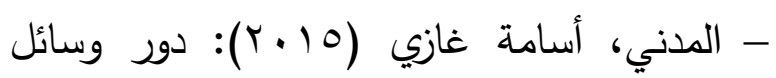
الإعلام التفاعلي في تشكيل الرأي العام لدى طلبة

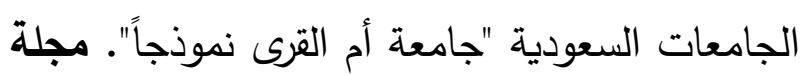

الآداب والعلوم ، جامعة السلطان قابوس، عُمان.

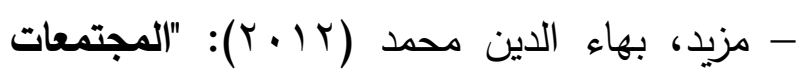
الافتراضية بديلاً للمجتمعات الواقعية، كتاب الوجوه نموذجاً". جامعة الإمارات العربية المتحدة.

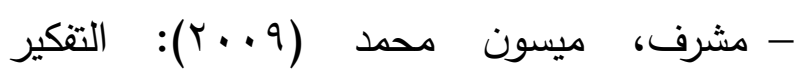

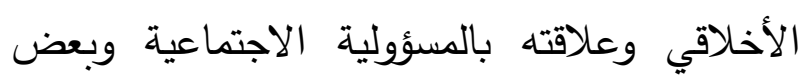
المتغيرات لاى طلبة الجامعة الإسلامية بغزة، رسالة ماجستير (غير منثورة)، كلية التربية، الجامعة الإسلامية، غزة.

- منصور، عبد الله (Y ( ا ب): تأثير وسائل الإعلام التقاعلي على جمهور المتلقين، "دراسة مقارنة للمواقع التفاعلي والمواقع الإكترونية العربية

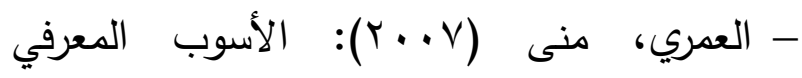
(التروي ـ الاندفاع) وعلاقته بالمسؤولية الاجتماعية

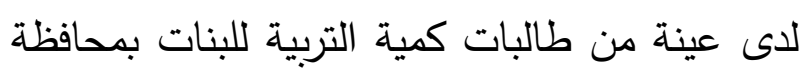
جدة. رسالة ماجستير (غير منشورة)، جامعة طيبة، المدينة المنورة.

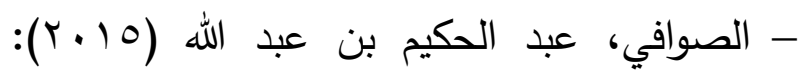

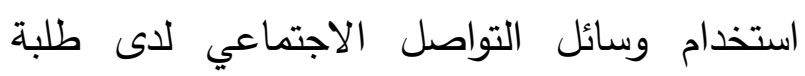
الحلقة الثانية من التعليم الأساسي في محافظة شمال الثرقية بسلطنة عمان وعلاقته ببعض المتغيرات. رسالة ماجستير (غير منشورة)، جامعة نزوى، كلية العلوم والدراسات الإنسانية.

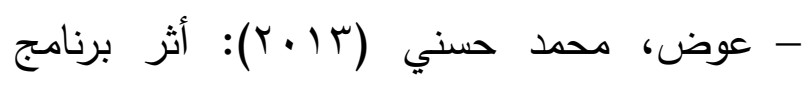

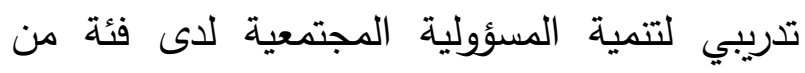

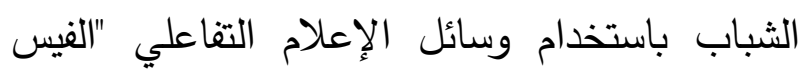
بوك". مجلة جامعة الثارقة للعلوم الانسانية

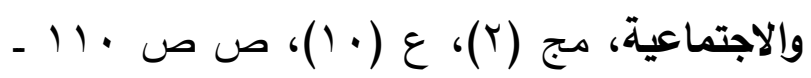
$.1 \% 9$

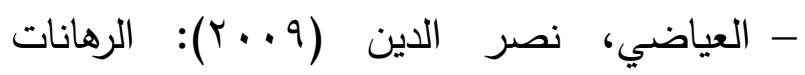
الأبستمولوجية والفلسفية للمنهج الكيفي نحو أفاق الهن

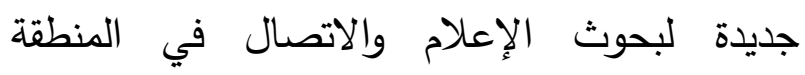
العربية. أبحاث المؤتمر الدولي " الإعلام الجديد: تكنولوجيا جديدة .... لعالم جديد"، جامعة البحرين،

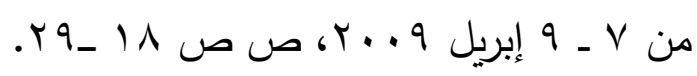

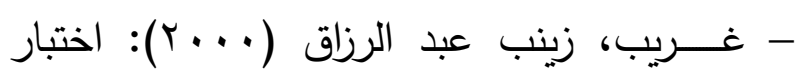
مدى فاعلية برنامج في تتمية مهارات الاتصال 
المجلة المصرية لبحوث الاعلام، ع(rV)، ص ص .rT

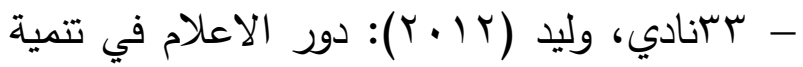

الانتماء لاى الطفل، الواقع والمأمول، معهد الدراسات

التربوية، جامعة القاهرة ، وزارة الثقافة الإدارية

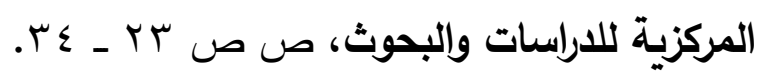

\section{ثانياً: المراجع الأجنبية}

- Beaudoin, C. E. (2008): Explaining the relationship between internet use and interpersonal trust: Taking into account motivation and information overload. Journal of Computer-Mediated Communication, 13(3): 550-568 (2008

- Beckwith, J., and F. Huang. (2005): Should we make a fuss? A case for social responsibility in science, Nature Biotechnology, 23(12), 147158.

- Christopher, S. E., Tiffany, M.F., Migual, D., and Michele R. (2000): The relationship of internet use to depression and social isolation among adolescents, Adolescence, 35 (138).

- English, R. \& Duncan-Howell, J.,(2008): Facebook Goes to College: Using Social Networking Tools to Support Students Undertaking Teaching Practicum. MERLOT Journal of Online Learning and Teaching, 4(4), PP. 596-601.

- Griffiths, M. (2003). 'Internet abuse in the workplace: issues and concerns fpr
أنموذجاً". رسالة ماجستير غير منشورة، كلية الآداب والتربية، الأكاديمية العربية في الدانمارك.

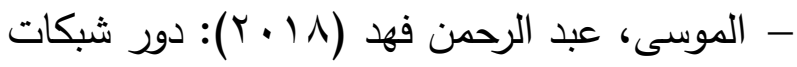
التواصل الاجتماعي في تعزيز تثقافة الثباب السعودي: دراسة ميدانية. رسالة ماجستير (غير فئير منشورة). كلية العوم الاجتماعية، جامعة نايف. - منصور، منال عبده (11 + (1): التأثيرات المترتبة العائة على استخدام الثباب الجامعي لموقع الفيس بوك. employers and employment counselor's'. Journal of employment Counseling, 40 PP.87-96.

- Marcel, D. (2009): Dictionary of media and com medications, M.E. Sharpe. NEW york .

- Michel, V,. (2010): Facebook and the invasion of technological communities, N.Y, New York.

- Reitz, M., (2012): Social Network Analysis: History Theory and Methodology, USA/ Australia: Sage Publications Ltd.

- Rowe, M. (2000): Internet use stunts social growth, The Stanford Daily, Online Available.

- Young, K. (1996): Internet addiction: The emergence of a new clinical disorder. University of Pittsburgh at Bradford. Paper Presented at the 104th annual meeting of the American Psychological Association, August 15,

- Toronto, Canada.

- Zarrella, D. (2010). The social media marketing. O'Reilly Media. 
TrE استخدام وسائل الإعلام التفاعلي لدى طالبات الدبلوم التربوي بجامعة جدة في ضوء بعض المتغيرات الديموغرافية

الإعلام التفاعلي على العلاقات الأسرية للشباب بالمنطقة الشرقية دارسة ميدانية. /https://rf.org.sa/sites/default/files - ميكبيديا الموسوعة الحرة، صموئيل تان (2008) https://ar.wikipedia.org/wiki https://mawdoo3.com/ -
ثالثاً: المراجع الإليكترونية: - - إحصائيات استخدام "الفايسبوك" في العالم، تم

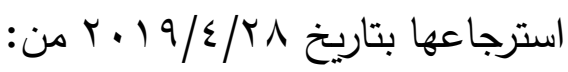
http://www.socialbakers.com - الخريف، فهذ بن عبد الرحمن؛ والعنزي، تركي بن مشهور (د. ت): آثار استخدام وسائل 


\title{
The Use of Interactive Media and its Relation to the Social Responsibility of University Students in the Light of Some Demographic Variables
}

\author{
Dr. Nabeela Bokhari \\ Assistant Professor of psychology at Jeddah University
}

\begin{abstract}
Twitter, Facebook, My Space, Google+, WhatsApp) among female students of educational diploma program at Jeddah University, and to reveal the reasons behind using interactive media sites, and to detect differences in the use of interactive sites and the level of social responsibility according to certain variables (Academic specialty, Parents' educational level, level of income). The sample consisted of (200) female students in the educational diploma Program in The Faculty of Education, University of Jeddah. The test prepared by the researcher measuring the use of sites and social responsibility were applied to the students. The results indicated that the highest percentages were as follows:

Use of interactive social sites daily, hours of use per day (Five hours or more), number of participants on page (200 and above), number of joined groups (5 groups), number of visits to favored sites per day (more than 5 times), and use of interactive social sites is at an all-time high. Examinees expect to minimize use of social sites in the future. Social networking app (WHATSAPP) was the most used platform. The results indicated that there are differences between students of scientific and literary specialization in the use of interactive media in favor of the scientific specialty. While there were no differences between the sample in the use of interactive media, social responsibility according to the level of education of parents, and the level of family income.

The study recommended to increase guidance and control on interactive media sites, and to improve the role of related establishments in guiding university students towards destinations that improve their culture.
\end{abstract}

Keywords: Interactive Media - University Students - Demographic Variables. 